\title{
Evolución de la definición y naturaleza de la autonomía universitaria en la jurisprudencia de la Corte Constitucional de Colombia*
}

\author{
An Overview of the Development of the Definition and Nature of Institutional Autonomy and Governance in \\ Higher Education, Drawn from the Case Law of the Constitutional Court of Colombia
}

\author{
Luis Felipe Gómez Restrepo S. J. ${ }^{\text {a }}$ \\ Pontificia Universidad Javeriana-Cali, Colombia \\ luisfelipesj@javerianacali.edu.co \\ ORCID: http://orcid.org/0000-0001-7036-6516 \\ Enrique Quintana López \\ Pontificia Universidad Javeriana-Cali, Colombia \\ ORCID: http://orcid.org/0000-0002-7976-661X \\ Nicolás Calderón Bolaños
Pontificia Universidad Javeriana-Cali, Colombia
ORCID: http://orcid.org/0000-0002-2632-6805
}

DOI: https://doi.org/10.11144/Javeriana.vj139.edna

Recepción: 12 Junio 2019

Aceptación: 10 Julio 2019

Fecha de publicación: 30 Diciembre 2019

\section{Resumen:}

En el este artículo se analiza el desarrollo histórico jurisprudencial que ha hecho la Corte Constitucional colombiana sobre la noción de Autonomía universitaria[1] y tratar de identificar la naturaleza jurídica de este concepto y su alcance, lo que servirá como contexto para estudiar cómo la Corte Constitucional ha entendido y desarrollado esta institución que le asiste a las universidades del país. Para este efecto, se han estudiado cerca de cien sentencias que la Corte Constitucional ha dictado desde 1992, momento en que inició actividades, hasta el mes de agosto del 2018. Hemos tenido en cuenta sentencias de constitucionalidad, de revisión de tutela y de unificación jurisprudencial, que han sido sistematizadas de acuerdo con los escenarios constitucionales que plantean[2] y con la frecuencia de citación que hay entre ellas, cuyos resultados se plasman en dos documentos anexos de este artículo (ver anexo 1 , anexo 2 y anexo 3 ).

Palabras clave: autonomía universitaria, Corte Constitucional, universidades, derecho a la educación, sentencias de tutela, sentencias de constitucionalidad, sentencias de unificación jurisprudencial, estudiantes, derecho fundamental, garantía institucional.

\section{Abstract:}

This article thoroughly examines the historical development of the concept of "University autonomy" that has been drawn from the jurisprudence and case law of the Constitutional Court of Colombia since it commenced operations in 1992. It aims is to identify the core elements of University Autonomy, as well as its scope and range. This analysis will be useful to offer a comprehensive understanding of how the Constitutional Court of Colombia has shaped and developed this concept that underlies the educational system as a whole, but is explicitly applicable to all the local universities, regardless of their public or private nature. To this end, we collected and analyzed close to one hundred (100) court rulings, from the year 1992 to 2018, regarding the specific topic of University Autonomy. Said rulings were reviewed and systematized, extracting the relevant legal precedents applicable to several disciplinary, civil, and constitutional legal cases that derive from our topic of inquiry. These included constitutional rulings, actions of guardianship (legal mechanism listed in the Colombian Constitution to purvey swift justice regarding basic human rights), as well as rulings that unify jurisprudence. The rulings above have been standardized according to their corresponding constitutional scenarios, and the high frequency of quotations present among and between them. These results can be consulted in the annexes of this paper (see annex 1 , annex 2 and annex 3 ).

Keywords: University Autonomy, Constitutional Court, Universities, Right to Education, Actions of Guardianship, Constitutional Rulings, Jurisprudential Unification Rulings, Students, Fundamental Right, Institutional Guarantee.

Notas de autor

a Autor de correspondencia. Correo electrónico: luisfelipesj@javerianacali.edu.co 


\section{Introducción}

La autonomía universitaria es un pilar fundamental para una democracia, pues consolida la cohesión social al crear espacios de discusión y de generación de conocimiento independiente y plural, que ayudan a formar ciudadanos con pensamiento crítico y libre sobre la vida y la sociedad. En efecto, la pluralidad en la búsqueda de la verdad genera condiciones de participación reales en sociedad, evitando así visiones totalitarias. Este es el horizonte desde el cual se realiza la lectura y relectura de la autonomía universitaria (AU).

La Constitución de 1991 consagró por primera vez a la AU como una prerrogativa a favor de las entidades de educación superior del país y delegó el desarrollo de esta garantía al legislador, quien posteriormente se encargó de darle un alcance concreto en la ley 30 de 1992. En consecuencia, la Corte Constitucional, desde el inicio de su actuar judicial en el año 1992, ha venido estableciendo distintas formas de la naturaleza de la AU como figura jurídica, lo cual ha significado una evolución conceptual de importantes implicaciones prácticas para las entidades de educación superior del país. Esto se debe a que es a partir de la definición de esta prerrogativa y su alcance que se puede determinar cuándo el acto de una universidad resulta desmedido frente a su autonomía, o cuándo la regulación del Estado es violatoria de esta garantía. Por esta razón, uno de los objetivos de este artículo es hacer una aproximación concreta de la naturaleza de la AU, tratar de establecer la mejor noción de esta figura y dejar en evidencia su evolución.

Debido a que la Corte Constitucional es la fórmula de cierre en la revisión de tutelas, revisión de constitucionalidad de leyes y de unificación de jurisprudencia constitucional, se revisó y estudió la gran mayoría de fallos ${ }^{[3]}$ en los cuales se ha pronunciado la Corte sobre la AU, para, a partir de ahí, identificar la naturaleza y definición jurídica que la Corte le ha dado a la AU, documentando además aquellos aciertos o yerros que se considere que estén presentes en este proceso de construcción jurisprudencial.

Hecha la revisión jurisprudencial propuesta, se presenta las conclusiones que se deriven de los hechos documentados, lo cual además se evidencia en dos anexos de este escrito que contienen los escenarios constitucionales de cada una de las sentencias revisadas y una relación de citas entre los fallos estudiados. Esto permitirá identificar con facilidad cuáles son los pronunciamientos de la Corte que esta cita con más frecuencia en su jurisprudencia, con lo cual se obtiene de forma amplia una especie de "nicho citacional".

\section{Desarrollo normativo de la AU}

El orden normativo tiene, en la actualidad, su punto de partida en la Constitución de 1991, la cual consagró la importancia de la autonomía universitaria, y por esta razón el presente estudio toma esta norma como punto de partida.

La Constitución Política de 1991 consagra en su Artículo 69 ${ }^{[4]}$ a la Autonomía Universitaria así:

Art. $69^{[5]}$. "Se garantiza la autonomía universitaria. Las universidades podrán darse sus directivas y regirse por sus propios estatutos, de acuerdo con la ley.

La ley establecerá un régimen especial para las universidades del Estado. El Estado fortalecerá la investigación científica en las universidades oficiales y privadas y ofrecerá las condiciones especiales para su desarrollo. El Estado facilitará mecanismos financieros que hagan posible el acceso de todas las personas aptas a la educación superior".

De la lectura de este artículo resulta evidente que el constituyente no hace una definición conceptual de la $\mathrm{AU}$, sino que solo se limita a consagrar este derecho en forma de garantía y proponer un horizonte enmarcado en la posibilidad que tienen las universidades de "darse sus directivas y regirse por sus propios estatutos", todo lo cual deberá estar dentro de una regulación legal que el mismo artículo propone.

De lo anterior, la ausencia de una definición conceptual dentro de la Constitución Política no es objeto de reproche, ya que se entiende que esto puede ser contrario a la técnica misma con la que este tipo de normas 
deben ser construidas. De ahí que no sea, entonces, procedente hacer la definición de los mismos derechos que se consagran.

Sin embargo, sí se encuentra como un punto de crítica el alcance que la norma le da a este derecho de forma escueta, resumiéndolo básicamente en los ejes antes señalados, a pesar de que, como se verá más adelante, la AU es una institución con amplio alcance, que no abarca solamente los aspectos de gobernanza y regulación normativa interna.

A pesar de esta crítica, es importante reconocer a nivel normativo la consagración de la AU como una prerrogativa constitucional que representó un sustantivo avance para el país ${ }^{[6]}$, debido a que contiene un reconocimiento tácito a la valiosa tarea que realizan las universidades al interior de una sociedad. Dicha tarea consiste en la formación de nuevas generaciones de profesionales y la producción de nuevo conocimiento en virtud de la investigación y los aportes de servicio a la comunidad como resultado de la extensión, tareas que históricamente han estado marcadas por una tensión permanente por impedir injerencias indebidas de terceros en la labor académica y científica que se realiza. Es por tal razón que la educación superior es el germen de esta figura jurídica y la razón por la cual se formula como garantía y no como un simple derecho.

Este hecho no es fortuito, ya que al estudiarse el proceso de formulación de la AU se encuentra que el poder constituyente a cargo de esta tarea estuvo conformado por 70 delegatarios, representantes de distintos partidos políticos y grupos de interés ante la Asamblea Nacional Constituyente, en quienes siempre fue manifiesta la intención de consagrar la AU como precepto constitucional dentro del marco del Proyecto de Reforma Constitucional que se adelantó en 1991. Este esfuerzo transversal que se hizo presente en diversos debates, informes y ponencias presentados por los constituyentes da cuenta del interés general que estuvo latente en el seno de la Asamblea Nacional Constituyente por el efectivo reconocimiento y consagración de la AU a nivel constitucional, como se refleja en numerosas Gacetas Constitucionales ${ }^{[7]}$ de la República de Colombia donde se consignaron las propuestas referidas.

En este sentido, la única divergencia que se presentó entre las propuestas sometidas a consideración por el poder constituyente primario ante la Asamblea, más allá de su contenido, versa sobre la decisión de reconocer a la AU como una garantía institucional o como un derecho fundamental al incluirla en el articulado de la nueva Constitución Política. Sobre el particular, es de especial relevancia citar la Gaceta Constitucional n. ${ }^{\circ} 5^{[8]}$, donde consta, por primera vez, una propuesta que pretende la consagración a nivel constitucional de la AU. Dicha propuesta fue presentada por el propio Gobierno de turno y, en su estructura de articulado, se incluyó a la AU bajo el capítulo De los Derechos Fundamentales, estipulando el contenido primigenio de este principio bajo los siguientes términos:

"Se garantiza la autonomía universitaria. Toda universidad podrá regirse por sus propios estatutos, sin perjuicio de la inspección que ejerza el Estado sobre la calidad y eficiencia de la educación. La estructura interna y el funcionamiento de las universidades responderán a principios democrático" $[9]$.

Muchas otras propuestas, informes y ponencias ante la Asamblea no solo siguieron el modelo presentado por el Gobierno nacional al mencionar a la $\mathrm{AU}$ en sus intervenciones, sino que se adhirieron a la iniciativa de dotarla de la entidad de derecho fundamental, a saber: la Gaceta Constitucional n. ${ }^{\circ}$ 34, presentada por la Asociación Colombiana de Universidades (ASCUN), incorporó el artículo correspondiente a la AU bajo el capítulo De los Derechos Fundamentales y, paralelamente, en su exposición de motivos ofreció la siguiente reflexión:

“(...) De ahí que se proponga el nombramiento libre de sus autoridades y el manejo autónomo de sus recursos, y se precise que la libertad en lo estatutario cobija no sólo los aspectos reglamentarios del funcionamiento mismo de la universidad, su organización, sino también en el campo curricular como transmisora de conocimientos, y en lo científico y tecnológico" [10].

Así mismo, la propuesta contenida en la Gaceta Constitucional n. ${ }^{\circ} 4^{[11]}$, en lo que respecta a la AU, fue de idéntico contenido y espíritu a la propuesta elevada por el gobierno nacional, en los términos antedichos. 
La propuesta contenida en el Proyecto de Acto Reformatorio de la Constitución Política de Colombia n. ${ }^{\circ} 13^{[12]}$ también tuvo la intención manifiesta de consagrar a la AU como un derecho fundamental, al igual que la propuesta contenida en el Proyecto de Acto Reformatorio de la Constitución Política de Colombia n. ${ }^{\circ}$ 126-B ${ }^{[13]}$.

Hasta este punto, algunas de las propuestas incluían en su articulado la libertad de cátedra e investigación y la libertad para elegir a sus rectores y directivas como elementos propios o complementarios a la AU, pero es la propuesta presentada por la Universidad de la Salle ${ }^{[14]}$ la que hace un estudio más acucioso para delimitar y concretar el contenido definitivo de la $\mathrm{AU}$ en el articulado de la nueva constitución. Esto se logró mediante la iniciativa de suprimir lo concerniente a la investigación y a la elección de rectores, "la primera porque está implícita en la misma naturaleza de la universidad y la segunda porque es cuestión reglamentaria"[15]. La Gaceta Constitucional n. ${ }^{\circ}{ }^{[16]}$ da cuenta de los artículos de la Constitución Política de Colombia que fueron aprobados en primer debate y, una vez más, el articulado referente a la $\mathrm{AU}$ fue categorizado por el poder constituyente bajo la denominación de Los Derechos Fundamentales, las Garantías y los Deberes. Un último antecedente relevante dentro del seguimiento que se ha hecho a la consagración de la AU como principio constitucional es el de la Gaceta Constitucional n..$^{\circ} 14^{[17]}$, que promulgó la nueva Constitución Política de la República de Colombia, incluyendo en el artículo 69 de la Constitución todo lo relativo a la AU, con el contenido íntegro del artículo referido como lo conocemos en la actualidad.

En suma, la intencionalidad del poder constituyente primario siempre fue manifiesta en el sentido de propender por la consagración de la AU como precepto constitucional, haciéndose evidente, además, que el espíritu del constituyente fue, desde el comienzo, dotar a la AU con el reconocimiento y calidad de derecho fundamental a la luz de la Constitución Política de la República de Colombia promulgada en el año 1991, toda vez que las intervenciones y propuestas fueron, en cuestión de números, de mayor asiduidad al momento de manifestar dicha intención.

Siguiendo el orden propuesto, se encuentra la primera consagración legal que se hace en Colombia de la AU, que reposa en el Artículo 28 de la ley 30 de $1992^{[18]}$, norma que organiza el servicio público de la educación superior. Inicialmente, resulta coherente que sea en esta norma en donde se reseñe la AU, ya que al ser la ley general que regula la educación superior del país, es la norma más acorde con el desarrollo de la AU. El texto que trae la ley es el siguiente:

Art. 28. "La autonomía universitaria consagrada en la Constitución Política de Colombia y de conformidad con la presente ley, reconoce a las universidades el derecho a darse y modificar sus estatutos, designar sus autoridades académicas y administrativas, crear, organizar y desarrollar sus programas académicos, definir y organizar sus labores formativas, académicas, docentes, científicas y culturales, otorgar los títulos correspondientes, seleccionar a sus profesores, admitir a sus alumnos y adoptar sus correspondientes regímenes, y establecer, arbitrar y aplicar sus recursos para el cumplimiento de su misión social y de función institucional".

Al consagrar la AU, este artículo no hace ningún tipo de definición conceptual de la misma, sino que procede a hacer un listado, que se entiende enunciativo y no taxativo, de las distintas atribuciones y libertades que tienen las universidades del país en virtud de la AU.

Iniciando por lo positivo, encontramos que esta norma es mucho más generosa que la Constitución Política en cuanto a alinderar el alcance de la AU, lo cual resulta lógico, porque, al ser la ley la norma llamada a desarrollar la Constitución, este era el espacio idóneo para demarcar el campo de acción que tienen las universidades en ejercicio de su AU. De igual forma, se destaca que la norma supera los aspectos de gobernanza y regulación interna que señalaba la Constitución, incluyendo otros escenarios de vital importancia para el quehacer universitario, tales como:

- Crear, organizar y desarrollar sus programas académicos.

- Definir y organizar sus labores formativas, académicas, docentes, científicas y culturales.

- Otorgar los títulos correspondientes. 
- Seleccionar a sus profesores.

- Admitir a sus alumnos.

- Adoptar sus correspondientes regímenes.

- Establecer, arbitrar y aplicar sus recursos para el cumplimiento de su misión social y de función institucional.

A pesar de lo anterior, esta norma no se ocupa de ofrecer una definición conceptual de la AU, lo que se considera una omisión importante por parte del legislador, ya que tener una definición legal y única de esta garantía constitucional permite un ejercicio más consciente por parte de las universidades y a los jueces y entes de control, intervenir con mayor facilidad y unidad de criterio en los conflictos que se susciten a partir de las actuaciones de las universidades y que puedan contener un abuso del derecho. Por lo tanto, se considera que el legislador pudo haber hecho una consagración más amplia desde lo conceptual, con lo cual habría hecho un valioso aporte al desarrollo de la AU en el país.

El panorama normativo que regula la $\mathrm{AU}$ actualmente en el país, que sirve de fundamento para que los jueces constitucionales resuelvan las eventuales tensiones que se presenten entre la $\mathrm{AU}$ y los derechos de los particulares a través de sus fallos, permite el desarrollo de los linderos, contenido y naturaleza de esta figura, aspectos sobre los cuales se hace un estudio a continuación.

\section{Desarrollo jurisprudencial de la AU}

Una vez revisado el ámbito legal, se procede a revisar el desarrollo jurisprudencial que ha hecho la Corte Constitucional, corporación que desde su nacimiento ha abordado con más o menos claridad la naturaleza y alcances de la AU. No obstante, vemos que en distintos momentos ha mostrado que no hay una unidad de criterio alrededor de esta garantía.

Como referencia primigenia y más reiterada por la jurisprudencia constitucional, se encuentra la que trae la sentencia T-492 de 1992, que establece:

\footnotetext{
“En ejercicio de su autonomía las universidades gozan de libertad para determinar cuáles habrán de ser sus estatutos; definir su régimen interno; estatuir los mecanismos referentes a la elección, designación y periodos de sus directivos y administradores; señalar las reglas sobre selección y nominación de profesores; establecer los programas de su propio desarrollo; aprobar y manejar su presupuesto; fijar, sobre la base de las exigencias mínimas previstas en la ley, los planes de estudio que regirán su actividad académica, pudiendo incluir asignaturas básicas y materias afines con cada plan para que las mismas sean elegidas por el alumno, a efectos de moldear el perfil pretendido por cada institución universitaria para sus egresados.

En síntesis, el concepto de autonomía universitaria implica la consagración de una regla general que consiste en la libertad de acción de los centros educativos superiores, de tal modo que las restricciones son excepcionales y deben estar previstas en la ley, según lo establece con claridad el artículo citado"[19].
}

En principio, en esta cita la Corte no entra a hacer una definición conceptual de la AU, sino que la aborda desde un inventario no taxativo, pues es de tipo enunciativo y no restrictivo, de atribuciones prácticas y operativas que tienen las universidades como titulares de esta garantía, y posteriormente resume su contenido en una especie de "libertad de acción" ${ }^{[20]}$ de que gozan los centros universitarios, la cual solo encuentra su límite en la ley y de manera excepcional.

Vale la pena reseñar que esta sentencia, al igual que varias de las primeras sentencias de la Corte Constitucional sobre este tema, destacan con considerable extensión al origen histórico de la AU, lo cual tiene sentido atendiendo el novedoso carácter de esta figura dentro del derecho nacional. Prueba de esto es la sentencia T-598 de 1992, que destina gran parte de sus consideraciones a describir el contexto histórico que vio nacer a la $\mathrm{AU}$, así como su necesidad jurídica.

"Este derecho a la autonomía universitaria, originariamente se orientaba a evitar que el poder público sometiera la ciencia, el conocimiento, la técnica y por, sobre todo, la función crítica de los centros docentes. Era la época de la nítida distinción 
entre los límites de los espacios del conocimiento y los del ejercicio de la función gobernante. Era la época de los fueros de la UNIVERSITAS medieval que fueron recogidos por el derecho positivo del Estado Liberal Clásico, como una expresión más del culto a la razón”.[21]

Hasta aquí se tienen las primeras expresiones de la corte sobre la AU, manifestaciones que se consideran generosas desde la descripción del alcance y límites, así como desde el reconocimiento de su importancia y necesidad. Sobre esto es importante resaltar dos puntos: en primer lugar, la necesidad de garantizarle a las universidades la no intromisión de los poderes públicos en su quehacer académico y, en segundo lugar, la relevancia que tiene asegurar la función crítica que cumplen las universidades en la sociedad.

Sin embargo, la Corte, en otra sentencia posterior, aborda la AU intentando definirla desde una comprensión negativa, señalando qué no es AU. Esto se puede ver en lo que dice la sentencia T-425 de 1993:

"La autonomía universitaria no consiste en la autorregulación absoluta de los centros de enseñanza superior, hasta el punto de desconocer el contenido esencial del derecho fundamental a la educación, ya que dicha autonomía se entiende que debe estar encausada siempre en aras del objetivo para el cual la consagró el Constituyente, esto es la educación, concebida por él como un servicio público que tiene una función social (Art. 67)”. [22]

Esta consideración de la corte resulta novedosa frente a los desarrollos anteriores, no solo por hacer una reflexión a partir de lo que no es la $\mathrm{AU}$, sino que, además, consagra un objetivo direccionado del ejercicio de esta figura. Es decir, si en la sentencia T-492 de 1992 se afirmaba que el contenido de la AU es darles a las universidades una "libertad de acción", en esta sentencia se dice que esa libertad de acción solo tiene legitimidad si se encamina a un objetivo, que es la educación, entendida esta como un servicio público con función social. A pesar de lo obvio que puede resultar la anterior consideración, no es de menor calibre su reseña, puesto que lo indicado en esta sentencia, en últimas, se debe entender como una limitante de la AU.

Ahora bien, durante este mismo año, el magistrado ponente Vladimiro Naranjo tuvo oportunidad de presentar una muy interesante y completa definición de AU, que quedó plasmada en la sentencia T-123 de 1993:

"La autonomía universitaria es un principio pedagógico universal que permite que cada institución tenga su propia ley estatutaria, y que se rija conforme a ella, de manera que proclame su singularidad en el entorno, mientras no vulnere el orden jurídico establecido por la Constitución y las leyes. Es el derecho de cada institución universitaria a ser lo que es, el derecho a su propia ley que la identifica como ente singular dentro del mundo universitario, de tal modo que puede autorregularse, pero nunca en contradicción con la legalidad y la conveniencia generales.".

De esta definición se resalta el carácter identificador que esta sentencia le otorga a la AU, es decir, la reconoce como el instrumento mediante el cual una universidad decide marcar y afianzar su identidad ante la sociedad académica, permitiendo desarrollar las singularidades que la hacen diferente a las demás. Dicho de otro modo, este factor diferenciador se convierte, en el fondo, en un aporte plural a una vida en democracia.

Este hecho no es de menor importancia, sobre todo porque la identidad es tal vez uno de los atributos más importantes que puede tener una institución de educación superior, y cuando la $\mathrm{AU}$ es reconocida como su medio de desarrollo, se genera entonces un vínculo indisoluble entre esta garantía y su titular.

En el año 1994, la Corte dictó la sentencia C-299, la cual tiene una especial particularidad que consiste en la argumentación del salvamento de voto que hicieron los magistrados Hernando Herrera Vergara y Vladimiro Naranjo Mesa, quienes se apartaron del alcance que la sala le dio a la AU, profundizando en su salvamento un alcance de carácter restrictivo, sobre todo, para el espectro de las entidades de educación superior de naturaleza pública. Dicen de forma expresa los magistrados en su salvamento de voto:

\footnotetext{
"La autonomía universitaria está referida básicamente a la cátedra, la investigación científica, los programas de formación superior, la discusión académica, la comunidad científica y su extensión, es decir, a la vivencia estrictamente académica de la Institución, que es el devenir mismo de la comunidad científica, y no a los aspectos meramente administrativos, sobre todo tratándose, como es el caso de la Universidad Nacional, de un establecimiento oficial de educación superior. Es por ello que constituye una impropiedad entender que la autonomía universitaria — esencialmente académica - se extiende a todos los
} 
aspectos extra-curriculares y extra-académicos, porque ello implica ir más allá del objeto jurídico amparado por la naturaleza de la autonomía" ${ }^{[24]}$.

A pesar del carácter no vinculante que tiene un salvamento de voto, las consideraciones hechas por estos magistrados resultan interesantes y darían pie para todo un debate al respecto, ya que, si se revisan los orígenes históricos de la $\mathrm{AU}$, se concluye que estos sí atendían a un carácter enteramente académico y no a aspectos administrativos o de otra índole. Sin embargo, no se comparte esta postura porque se considera que hacer esta interpretación del alcance de la AU restringe de forma excesiva la figura, al punto de llegar a hacerla inoperante. La razón de esto es que, en la práctica, independizar el aspecto netamente académico de los hechos administrativos o financieros de la universidad resulta una operación muy difícil y, predeciblemente, destinada al fracaso. Por este motivo, se prefiere entender el alcance de la AU como un espacio amplio donde convergen todos los elementos propios del quehacer universitario, siendo cada uno de estos aspectos necesarios para el adecuado desarrollo académico y administrativo de una universidad.

En el año 1995 la Corte hace un intento de definición de la AU, en el cual no se limita simplemente a indicar sus alcances y contenidos, sino que se aventura a conceptualizarla de forma más o menos precisa. Lo descrito se puede evidenciar en la sentencia T-512 de 1995, que señala:

"La autonomía universitaria se traduce en un ámbito definido de libertad institucional para resolver los problemas que surgen en la comunidad que integran profesores y estudiantes" ${ }^{" 25]}$.

Resulta interesante este abordaje de la Corte, no solo porque de forma concreta intenta definir la AU, sino porque de la lectura del extracto citado se puede entender que el objeto de la AU es atender a la resolución de conflictos propios del quehacer universitario, lo cual, si bien es cierto, no coincide con lo que la misma Corte dijo en el fallo T-425 de 1993, antes revisado. Sobre este punto, vale la pena señalar que en la sentencia T-180 de $1996^{[26]}$ la Corte señala que el objeto final de la AU es evitar la intromisión ilegítima del Estado, con lo cual se encuentra entonces una tercera formulación sobre el objeto de este derecho:

La finalidad de la autonomía universitaria es la de evitar que el Estado, a través de sus distintos poderes, intervenga de manera ilegítima en el proceso de creación y difusión del conocimiento ${ }^{[27]}$.

En este orden de ideas, la sentencia T-515 de $1995^{[28]}$ recoge algunos de los desarrollos hechos en los fallos antes referidos y hace un aporte adicional al identificar el núcleo esencial de la AU, lo cual resulta sumamente importante dentro de esta construcción conceptual que hace la Corte, además, porque recoge de buena manera los ejes esenciales sobre los que gira el quehacer universitario. La Corte explica de la siguiente manera el concepto de núcleo:

"La educación puede ser encauzada y reglada autónomamente, pero no negada en su núcleo esencial.

Siguiendo a Peter Häberle, se denomina "contenido esencial" al ámbito necesario e irreductible de conducta que el derecho protege, con independencia de las modalidades que asuma el derecho o de las formas en que se manifieste. Es el núcleo básico del derecho fundamental, no susceptible de interpretación o de opinión sometida a la dinámica de coyunturas o ideas políticas" ${ }^{29]}$.

La Autonomía Universitaria, como realidad histórica se fundamenta, según Alfonso Borrero S. J., en la autonomía de la ciencia y el saber:

"La autonomía surgida con la base en la ciencia y el saber, tiene su fundamento en el objeto social, y es precisamente ahí donde cobra todo su valor.

La universidad hace suyo el poder propio del saber, pero sin menoscabo de los valores consagrados constitucionalmente. Esto no obsta para que las universidades, en procura de formar individuos en la ciencia y el saber, determinen los mecanismos académicos capaces de comprobar la idoneidad del educando. En efecto, la Universidad debe trasmitir al interior de la comunidad universitaria los mayores niveles de exigencia, en razón de obtener una integral formación. Razón por la cual los 
reglamentos académicos señalan las reglas de juego a las que se compromete el estudiante una vez este por su propia voluntad decide ingresar a la institución, previo proceso de selección efectuado por el establecimiento universitario" ${ }^{\text {[30] }}$.

A pesar del corto periodo de tiempo que se ha revisado en la jurisprudencia constitucional hasta aquí, se resaltan los múltiples aportes que ha hecho la Corte en sus aproximaciones conceptuales, los cuales, a pesar de no ser uniformes en sus apreciaciones, sí se valoran por su contenido.

Otro enfoque que la Corte ha usado para abordar conceptualmente a la AU es darle el rango de garantía constitucional, lo cual difiere en su función con la naturaleza de derecho. Toda vez que se hable de garantía se presume la existencia de un riesgo que se debe conjurar, ya que es una carga irresistible o indeseable, noción distinta a la de derecho que responde más a un atributo propio de la persona titular del mismo. Sobre esto, la sentencia C-337 de 1996 señala una definición novedosa de garantía institucional, la cual, como se verá más adelante, termina siendo acogida por la Corte de forma reiterada:

"Conviene precisar que en virtud de lo dispuesto por el artículo 69 constitucional, la autonomía universitaria se constituye en una garantía institucional; es decir, en una "protección constitucional" que se les confiere a las instituciones que prestan el servicio de educación universitaria". [31]

Por otra parte, la Corte también ha señalado que la AU es un derecho contenido dentro del derecho a la educación, con lo cual perdería entidad propia para asumir un rol accesorio o subordinado ante otro derecho. Esto lo indica la Sentencia T-223 de 1996:

"No obstante lo anterior, la institución accionada goza, de conformidad con el artículo 69 de la Carta Política, de la autonomía
universitaria como parte integrante del derecho fundamental a la educación, la cual le otorga la libertad de que gozan los
centros universitarios para fijar en sus estatutos generales el régimen interno o reglamentario, en el que se estipulan las
disposiciones que se aplican a las diferentes situaciones que, con ocasión a las actividades que realiza la misma institución,
bien sean de tipo académico, disciplinario o administrativo, son necesarias para el cumplimiento de sus objetivos". ${ }^{[32]}$

Esta concepción de la AU no se ajusta a la que previamente había venido expresando la misma Corte y presenta en su práctica unas dificultades de titularidad de derechos, ya que el derecho a la educación no se predica sobre los mismos sujetos que la AU. Es decir, la AU como derecho encuentra sus titulares naturales en las instituciones universitarias, mismas que, a su vez, no son titulares del derecho a la educación, el cual, por esencia, radica en cabeza de los ciudadanos en general, y los estudiantes en particular, por lo cual no se considera acertada su formulación al desconocer la entidad propia que tiene la AU.

En el año 1997, la Corte nuevamente propone una definición de AU a través de la sentencia C-220 de 1997, la cual presenta un concepto que tiene como fundamento la noción de libertad jurídica que propone Kant, lo que lleva a asimilar a la AU con el concepto de libertad, que no había sido expuesto previamente por la Corte Constitucional y que hace cuestionarse si esta definición es del todo aceptable.

“(...) El principio de autonomía universitaria, que en las sociedades modernas y post-modernas se considera como uno de los pilares del Estado democrático, pues sólo a través de ella las universidades pueden cumplir la misión y objetivos que le son propios y contribuir al avance y apropiación del conocimiento, el cual dejando de lado su condición de privilegio, se consolida como un bien esencial para el desarrollo de los individuos y de la sociedad; dicho principio se traduce en el reconocimiento que el Constituyente hizo de la libertad jurídica ${ }^{[33]}$ que tienen las instituciones de educación superior reconocidas como universidades, para autogobernarse y autodeterminarse, en el marco de las limitaciones que el mismo ordenamiento superior y la ley les señalen"[34],[35].

Durante este mismo año, pero en la sentencia T-513 de 1997, la Corte presenta una doble definición de AU, primero, conceptualizándola como la capacidad de autodeterminación, y después, reiterando la noción de garantía, aunque continúa clasificándola como un derecho en cabeza de las entidades de educación superior:

"El principio de la autonomía universitaria es la capacidad de autodeterminación otorgada a las instituciones de educación superior para cumplir con la misión y objetivos que les son propios. 
En síntesis, se trata de una garantía que permite a los entes de educación superior darse su propia normatividad, estructura y concepción ideológica, con el fin de lograr un desarrollo autónomo e independiente de la comunidad educativa, sin la injerencia del poder político. Sin embargo, la autonomía universitaria no puede ser concebida como un derecho autónomo que puede desconocer las normas mínimas establecidas en la ley”.[36]

En la parte final del último extracto se podría considerar que hay un error de parte de la Corte cuando afirma que la AU no puede concebirse como un derecho autónomo, ya que esta figura sí es autónoma siempre que no depende de otro para su subsistencia o ejercicio. En ese sentido, se considera que lo que la Corte realmente quiso decir en el texto citado es que la $\mathrm{AU}$ no es una potestad absoluta, debido a que no puede desconocer a la Constitución y la ley, afirmación que la misma jurisprudencia de esta corporación ha reiterado en múltiples oportunidades.

En el año 1999, la Corte trae un desarrollo que se considera de suma importancia, puesto que permite unificar, o por lo menos comprender con coherencia, las nociones de AU que ha expuesto esta corporación, unas veces como derecho y otras como garantía. En concreto, la sentencia T-310 de $1999^{[37]}$ afirma:

"El artículo 69 de la Constitución de 1991 reconoce en forma expresa la autonomía de los centros de educación superior, como
una garantía institucional que busca preservar la libertad académica y el pluralismo ideológico, en los cuales se fundamenta
nuestro Estado Social de Derecho (C.P. art. $1^{\circ}$ ). Por consiguiente, esta facultad o atributo colectivo de la institución es
independiente pero inescindible de derechos subjetivos, que en ocasiones la complementan y en otras la limitan. Así pues, la
autonomía universitaria se relaciona íntimamente con las libertades de cátedra, enseñanza, aprendizaje e investigación (C.P.
art. 27), con los derechos a la educación (C.P. art. 67), al libre desarrollo de la personalidad (C.P. 16) y a escoger libremente
profesión u oficio (C.P. art. 26); lo cual explica por qué en algunas circunstancias puede ser vista como una garantía y en otras
como un 'derecho limitado y complejo"” [38].

De lo expuesto en este fallo se puede concluir una interesante noción de AU que consiste en entenderla como una figura bifronte, es decir que puede ser vista como derecho limitado y complejo o como una garantía constitucional, dependiendo del ámbito de aplicación, de los supuestos fácticos en que se ejerza y de la relación que tenga con otros derechos que estén en juego.

Este fallo permite apartarse de la impresión de dispersión de criterios de la Corte, para, por el contrario, asumir una postura de unificación que reconozca desde su complejidad a la AU. Igualmente, este fallo trae consigo un importante ejercicio jurisprudencial que consiste en revisar los pronunciamientos anteriores de la Corte y definir una serie de subreglas alrededor de la AU, lo que permite delinear algunos límites a esta figura. Esta labor fue expresada en esa oportunidad así:

14. A manera de sumario se resumirán las subreglas principales que la Corte Constitucional ha esbozado en el tema de la autonomía universitaria, a saber:

a) La discrecionalidad universitaria, propia de su autonomía, no es absoluta, ya que se encuentra limitada por el orden público, el interés general y el bien común. Sentencias T-492 de 1992, M. P. José Gregorio Hernández Galindo y T-649 de 1998, M. P. Antonio Barrera Carbonell.

b) La autonomía universitaria también se limita por la inspección y vigilancia de la educación que ejerce el Estado. Sentencia C-194 de 1994, M. P. Vladimiro Naranjo Mesa; C-547 de 1994, M. P. Carlos Gaviria Díaz; y C-420 de 1995, M. P. Hernando Herrera Vergara.

c) El ejercicio de la autonomía universitaria y el respeto por el pluralismo ideológico demuestran que los centros superiores tienen libertad para determinar sus normas internas, a través de los estatutos, las cuales no podrán ser contrarias a la ley ni a la Constitución. Sentencias T-123 de 1993, M. P. Vladimiro Naranjo Mesa; T-172 de 1993, M. P. José Gregorio Hernández Galindo; T-506 de 1993, M. P. Jorge Arango Mejía; y T-515 de 1995, M. P. Alejandro Martínez Caballero.

d) Los estatutos se acogen voluntariamente por quienes desean estudiar en el centro educativo superior, pero una vez aceptados son obligatorios para toda la comunidad educativa. El reglamento concreta la 
libertad académica, administrativa y económica de las instituciones de educación superior. Sentencia C-547 de 1994, M. P. Carlos Gaviria Díaz y T-237 de 1995, M. P. Alejandro Martínez Caballero.

e) El legislador está constitucionalmente autorizado para limitar la autonomía universitaria, siempre y cuando no invada ni anule su núcleo esencial. Por lo tanto, existe control estricto sobre la ley que limita la autonomía universitaria. Sentencias T-02 de 1994, M. P. José Gregorio Hernández Galindo; C-299 de 1994, M. P. Antonio Barrera Carbonell; C-06 de 1996 y C-053 de 1998, M. P. Fabio Morón Díaz.

f) La autonomía universitaria es un derecho limitado y complejo. Limitado porque es una garantía para el funcionamiento adecuado de la institución. Es complejo, ya que involucra otros derechos de las personas. Sentencias T-574 de 1993, M. P. Eduardo Cifuentes Muñoz y T-513 de 1997, M. P. Jorge Arango Mejía.

g) Los criterios para selección de los estudiantes pertenecen a la órbita de la autonomía universitaria, siempre y cuando aquellos sean razonables, proporcionales y no vulneren derechos fundamentales y en especial el derecho a la igualdad. Por ende, la admisión debe corresponder a criterios objetivos de mérito académico individual. Sentencias T-187 de 1993, M. P. Alejandro Martínez Caballero; T-02 de 1994, M. P. José Gregorio Hernández Galindo; T-286 de 1995, M. P. Jorge Arango Mejía; T-774 de 1998, M. P. Alfredo Beltrán Sierra; T-798 de 1998, M. P. Vladimiro Naranjo Mesa y T-019 de 1999, M. P. Eduardo Cifuentes Muñoz.

h) Los criterios para determinar las calificaciones mínimas deben regularse por reglamento, esto le corresponde a la autonomía universitaria. Sentencia T-061 de 1995, M. P. Hernando Herrera Vergara; T-515 de 1995 y T-196 de 1996, M. P. Alejandro Martínez Caballero.

i) Las sanciones académicas hacen parte de la autonomía universitaria. Sin embargo, son de naturaleza reglada, ya que las conductas que originan la sanción deben estar previamente determinadas en el reglamento. Así mismo, la imposición de sanciones está sometida a la aplicación del debido proceso y del derecho de defensa. Sentencia T-237 de 1995, M. P. Alejandro Martínez Caballero y T-184 de 1996, M. P. Antonio Barrera Carbonell ${ }^{[39]}$.

Se exalta el valor que este fallo tiene dentro del histórico de la Corte sobre pronunciamientos relacionados, ya que no solo da una luz clara sobre la naturaleza de la AU, sino que, además, establece una serie de criterios de suma utilidad para dirimir eventuales tensiones de derechos relacionadas con la AU.

A pesar de la claridad aportada en la Sentencia T-310 de 1999, la Corte posteriormente realiza otras aproximaciones conceptuales sobre la $\mathrm{AU}$, sin que realmente se contribuya con mayor novedad en el contenido de las definiciones ofrecidas.

Sin embargo, sí se encuentran conceptualizaciones interesantes sobre el contenido de la AU desde un enfoque estructural, tal como lo hace la sentencia C-1435 del 2000, la cual divide en dos grandes partes a la AU, de acuerdo con los supuestos fines que persigue para, desde ahí, desarrollar las libertades o facultades especiales que tiene toda institución universitaria como titular de esta atribución. Lo dicho por este fallo, si bien no es nuevo en su contenido, resulta exaltable por la forma esquemática en que presenta estos conceptos:

\footnotetext{
"Así, teniendo en cuenta la filosofía jurídica que ampara el principio de autonomía universitaria, la Corte ha definido su alcance y contenido a partir de dos grandes campos de acción que facilitan la realización material de sus objetivos pedagógicos: (1) la autorregulación filosófica, que opera dentro del marco de libertad de pensamiento y pluralismo ideológico previamente adoptado por la institución para transmitir el conocimiento, y (2) la autodeterminación administrativa, orientada básicamente a regular lo relacionado con la organización interna de los centros educativos. A partir de tales supuestos, es posible afirmar, como ya lo ha hecho la Corte, que el derecho de acción de las universidades se concretan en la posibilidad de: (i) darse y modificar sus estatutos; (ii) establecer los mecanismos que faciliten la elección, designación y períodos de sus directivos y administradores (iii) desarrollar sus planes de estudio y sus programas académicos, formativos, docentes, científicos y culturales; (iv) seleccionar a sus profesores y admitir a sus alumnos; (v) asumir la elaboración y aprobación de sus presupuestos y (vi) administrar sus propios bienes y recursos". ${ }^{[40]}$
} 
Avanzando en el estudio propuesto, resulta necesario hacer una mención especial a lo que la Corte Constitucional afirma en el fallo T-156 de $2005^{[41]}$, donde establece que la relación existente entre el derecho a la educación y la $\mathrm{AU}$ radica en que ambos principios persiguen los mismos fines y objetivos, los cuales se resumen en el desarrollo integral del individuo:

"El derecho a la educación encuentra su afinidad con la autonomía universitaria en cuanto a los fines y objetivos que persiguen, representados en el desarrollo libre, singular e integral del individuo y el cumplimiento de la mejor formación moral, intelectual y física de los educandos". ${ }^{[42]}$

Del análisis de esta afirmación surge una crítica similar a la antes hecha al fallo T-223 de 1996, pues no resulta del todo acertado indicar que la AU y el derecho a la educación persigan de forma común los mismos fines y objetivos. Como se indicó previamente, esos derechos, al estar en cabeza de dos sujetos de derecho completamente diferentes, persiguen finalidades distintas, pero a su vez complementarias, lo que hace a cada uno de estos una condición necesaria para el pleno y real ejercicio del otro, dándose así una relación que se basa más en el mutualismo y la complementariedad, que en la coincidencia de fines y objetivos.

Durante este mismo año 2005, la Corte Constitucional hace un ejercicio interesante de sistematización y análisis de la facultad de las universidades para expedir normas y reglamentos como expresión de su AU en el fallo T-933 de 2005, proyectando así tres enfoques desde los que pueden ser entendidos o vistos estos reglamentos:

"Bajo esos supuestos, este Tribunal ha señalado que el reglamento estudiantil puede ser analizado: (i) desde la perspectiva de la educación como un derecho deber; (ii) desde el punto de vista del derecho a la autonomía universitaria, y (iii) desde la óptica de su ubicación en el ordenamiento jurídico como norma con relevancia jurídica”. ${ }^{[43]}$

El desarrollo conceptual que hace la Corte en este fallo va a irrigar de forma muy clara muchos fallos posteriores, puesto que facilita la labor del juez constitucional para entender o determinar los alcances legítimos que tienen las normas que expiden las entidades de educación superior, con lo cual se puede determinar de mejor manera si ha habido actos que han desbordado ilegítimamente los linderos de la AU.

La Corte en su desarrollo jurisprudencial, y a partir de las constantes tensiones que se presentaban entre la AU y el derecho a la educación, optó por establecer una regla referida al juicio de ponderación que debe hacer el juez de tutela cuando estos dos derechos entran en conflicto. Esta regla se establece en la sentencia T-254 de 2007:

"En este último evento, se está frente al fenómeno de la concurrencia o coexistencia de derechos. Por un lado, el derecho constitucional a la educación y, por el otro, el derecho a la autonomía de los centros educativos, materializado en las obligaciones previstas en el reglamento estudiantil y las consecuencias que se derivan de su incumplimiento. Cuando estos dos derechos entran en conflicto y es posible su armonización, el juez debe proceder a realizar un juicio de ponderación a favor del derecho a la educación si la consecuencia del conflicto es su desconocimiento y negación. El propósito de la ponderación no es excluir o eliminar el derecho a la autonomía, sino establecer una prelación a favor del derecho a la educación en aras de impedir que sea suspendido o negado indefinidamente". [44]

Esta regla establecida por la Corte resulta de gran importancia porque crea una relación entre derechos que es coherente con la naturaleza de garantía institucional de la AU y el de derecho fundamental a la educación, lo que deber servir de guía para los jueces de tutela, sin que se entienda como razón para negar o vulnerar la AU. Además, la Corte también establece esta regla como una herramienta que debe ser usada por las autoridades universitarias, lo que evita que la aplicación ciega de sus reglamentos sea un medio para vulnerar el derecho a la educación de sus estudiantes:

“Considera la Sala que ante este tipo de eventos las autoridades universitarias no deben ser insensibles, dando aplicación ciega a las normas o escudándose en la autonomía universitaria y de espalda al drama humano que atraviesa uno de sus estudiantes, sino que en cada caso es necesario ponderar la trascendencia del problema frente al sacrificio que debe asumir la universidad con la permanencia de uno de sus educandos". [45] 
En el año 2008, la Corte presenta un aporte importante a la construcción de una noción jurídica de la AU a través de la sentencia C-162 de $2008^{[46]}$, pues entra a estudiar con sumo rigor la naturaleza de esta institución, señalando en un primer momento lo siguiente:

"Ahora bien, de la naturaleza jurídica de la figura contemplada en el artículo 69 constitucional se derivan importantes
consecuencias en cuanto a su alcance y comprensión. Como es sabido la categoría de garantía institucional es acuñada en los
años veinte de este siglo por la doctrina alemana para referirse a determinadas instituciones no esenciales o centrales, pero si
típicas, y por tanto necesarias, de la organización político administrativa. Gracias a su reconocimiento constitucional gozan
de protección, especialmente frente al legislador, pues a este último al regularlas le estaría vedado suprimirlas, vaciarlas de
contenido o desfigurarlas, con esta prohibición queda garantizada la imagen maestra de la institución o Leit-Bild" [47].

Lo primero que se puede extraer de esta cita es que la Corte en esta oportunidad se apartó de la noción bifronte expuesta en la sentencia T-310 de 1999 y de las demás definiciones que se referían a la AU como derecho, dándole así una naturaleza única de garantía institucional a la AU, lo que implica, entre otras cosas, una limitación al ejercicio legislativo del Congreso de la República, que podrá regularla, mas no eliminarla o vaciarla de contenido, punto en el que radica la noción de garantía institucional.

Dicho lo anterior, y continuando con la revisión de este fallo, se encuentra que al identificarse a la AU como una garantía institucional no se está garantizando un concepto concreto y pétreo, sino que se cuida la permanencia de unos elementos esenciales que permitan construir la identidad de la figura que atienden a condiciones de tiempo, modo y lugar, con esto, se hace una distinción definitiva del concepto de derecho fundamental. En la sentencia se puede ver así:

"En esa medida la garantía institucional no asegura un contenido concreto, ni un ámbito de competencias determinado e inmodificable, sino la preservación de los elementos identificadores de una determinada institución en términos reconocibles para la imagen que de la misma tiene la conciencia social en cada tiempo y lugar, de lo que resultarían importantes diferencias con la figura de los derechos fundamentales" ${ }^{[48]}$.

Ahora bien, esto tiene un efecto práctico referido a la facultad de las ramas legislativa y ejecutiva para regular la AU, pues al ser identificada como Garantía Institucional no debe ser confundida con la figura de Reserva Legal, instituciones que suponen efectos diferentes en su regulación según este fallo:

"Se concluye entonces que la garantía institucional y la reserva de ley persiguen propósitos diferentes, pues mientras la primera cumple una función de límite a la actividad legislativa, la segunda pretende precisamente lo contrario, es decir, garantizar que ciertos contenidos constitucionalmente predeterminados sean regulados en detalle exclusivamente por medio de normas con fuerza de ley. Nótese entonces que la reserva de ley no preserva necesariamente a una institución constitucionalmente garantizada, pues la detallada regulación legal puede conducir precisamente a erosionar sus rasgos distintivos (...)

Lo dicho anteriormente tiene plena vigencia en materia de la autonomía universitaria. Como se trata de una garantía institucional eso significa que su finalidad es asegurar a las instituciones de educación superior un ámbito de actuación que no puede ser desdibujado por los poderes públicos, el cual tiene por lo tanto origen constitucional y ha sido reconocido por la jurisprudencia constitucional con unos contenidos concretos a los que ya se hizo alusión, empero eso no significa que los límites a la autonomía universitaria deban tener origen legal, porque la Constitución no establece una reserva de ley en la materia. Cosa distinta es, como se expuso en el acápite anterior, que en virtud de la cláusula general de competencia legislativa y de la sujeción positiva del reglamento a la ley, las entidades que hacen parte de la rama ejecutiva del poder público, carezcan de una potestad normativa autónoma que pueda ser ejercida sin sujeción a las disposiciones legales que regulen la materia”[49].

Según lo anterior, es claro que la virtud de la AU como garantía institucional no radica en la necesidad de normas con fuerza de ley para su regulación, sino en la imposibilidad de que su contenido y características esenciales sean vaciadas o anuladas a través de regulaciones normativas, lo que marca una pauta clara referida a la regulación de la AU.

Del análisis de este fallo resulta evidente que la Corte acoge de forma clara la naturaleza de garantía institucional de la AU, dejando de lado la noción dual de garantía/derecho ${ }^{[50]}$ o derecho exclusivamente, y fijando de manera clara su postura de lado a la noción de garantía institucional, que se sustenta en una sólida argumentación jurídica y que la misma Corte recoge en otros fallos posteriores ${ }^{[51]}$. 
Esta tesis es posteriormente acogida por la misma Corte en su jurisprudencia, reiterando la naturaleza de garantía institucional y descartando la de derecho subjetivo por no tener los alcances propios de esta institución, ejemplo de esto es la sentencia T-689 de 2009:

"A partir del concepto de garantía institucional, esta Corporación también ha explicado las diferencias y relaciones que se presentan entre la autonomía y los derechos fundamentales. Así, la Corte ha expresado que la autonomía universitaria no tiene el alcance de un derecho subjetivo, sino que se trata de una forma de protección específica de las universidades, que se concreta en un conjunto de atribuciones, facultades y libertades y que tiene una seria incidencia en la eficacia de diversos derechos fundamentales, pero que no se encuentra por encima de estos" ${ }^{\text {[52] }}$.

Esta reiteración en la noción de garantía institucional resulta interesante, ya que, hasta la fecha, es la que se encuentra vigente en la jurisprudencia de la Corte Constitucional, no encontrándose aportes teóricos nuevos o diferentes en fallos posteriores.

A pesar de esto, se considera como un hecho poco técnico que algunos fallos de la Corte Constitucional posteriores al año $2008^{[53]}$ continúen refiriéndose a la AU como un derecho y no como una garantía institucional, pues puede llevar a empañar la claridad que esta corporación ha dado a la definición de esta figura.

Dicho lo anterior, y como último punto relevante del estudio jurisprudencial hecho, se encuentra que la Corte en sentencia T-276 de 2009, de nuevo, conceptualiza sobre la relación entre la AU y el derecho a la educación, señalando lo siguiente:

"Ahora bien, en el otro extremo del derecho a la autonomía universitaria se encuentra el derecho a la educación que de acuerdo con la jurisprudencia constitucional es de naturaleza fundamental y tiene el carácter de derecho-deber". ${ }^{[54]}$

Frente a esta afirmación, se considera que, nuevamente, la Corte erra al caracterizar la naturaleza de la relación existente entre la AU y el derecho de educación, ya que tal como se dijo antes, no hacen parte el uno del otro ni comparten fines comunes, así como tampoco son derechos antagónicos llamados siempre a rivalizar o generar tensión entre ellos. Por el contrario, se reitera, estos derechos están llamados a complementarse y ser condiciones necesarias para el adecuado ejercicio del uno y del otro, lo cual no significa que no puedan, eventualmente, verse enfrentados en determinados casos. Por esto, sí resulta importante señalar que, a pesar de esta posibilidad, no atiende a la naturaleza de estos derechos comprenderlos en un contexto de rivalidad permanente o inevitable, ya que eso atenta justamente contra un sano y normal ejercicio de estos derechos.

\section{Comentarios sobre la naturaleza de la AU}

En el análisis jurisprudencial desarrollado se identifican distintos aspectos relacionados con la AU que ameritan una mayor discusión o estudio. Sin embargo, siguiendo los objetivos propuestos en este escrito, resulta necesario enfocarse en lo expuesto por la Corte Constitucional sobre la naturaleza jurídica de la AU, ya que se considera que algunos puntos exigen una mayor discusión.

Así las cosas, y tal como se describió, la Corte desarrolló la noción de AU como garantía institucional en varias de sus sentencias ${ }^{[55]}$, tanto de tutela como de constitucionalidad, dejando claro que la AU responde a una única naturaleza, y descartándose así el tratamiento de derecho fundamental que, inicialmente, esta misma corporación había dado en sus fallos.

Esta dicotomía teórica sobre la AU entre Derecho Fundamental y garantía institucional no ha sido exclusiva de Colombia, ya que en países como España se ha planteado esta misma discusión, pero con resultados diferentes. 
En España, el Tribunal Constitucional a través del fallo STC 26 de 1987 se decantó por reconocer a la AU como derecho fundamental en vez de la noción de garantía institucional, lo cual explica Miguel J. Agudo Zamora así:

\begin{abstract}
"El artículo 27 declara, en efecto, en su apartado 10, que "se reconoce la autonomía de las Universidades, en los términos que la ley establezca”. Lo que es tanto como decir que, dentro de esos términos legales, la libertad académica de los centros de enseñanza universitaria goza de la misma protección constitucional que la otorgada a los demás derechos y libertades públicas fundamentales, incorporados a la sección $1^{a}$ del capítulo $2^{\circ}$ del título I de la Constitución. Por lo tanto, la ubicación del artículo $27 \mathrm{CE}$ ha servido de pie para calificar la autonomía universitaria como un derecho fundamental y, por tanto, requerir su desarrollo por Ley Orgánica (art. 81.2) con la exigencia de mayoría reformada que la misma requiere y que encuentra una limitación en el respeto del "contenido esencial" del derecho (art. 53.1 CE), así como el procedimiento de reforma agravado del artículo 168 CE Más aún, tal derecho fundamental es susceptible del amparo ordinario y constitucional (art. 53.2 CE y disposición transitoria 2 2a 2 de la Ley Orgánica 2/1979 del Tribunal Constitucional).

Esta calificación fue la que aceptó finalmente el Tribunal Constitucional (STC 26/87, de 27 de febrero), zanjando una divergencia doctrinal entre quienes sostenían esta tesis 15 y la de quienes optaban por configurar la autonomía como 'garantía institucional" $16^{[56]}$.
\end{abstract}

Esta distinción entre garantía institucional y derecho fundamental supone una importante diferencia práctica, que se manifiesta en la facilidad o dificultad con la cual el Estado puede entrar a intervenir la esfera íntima de la figura, ya que el derecho fundamental es la institución que ofrece una mayor resistencia ante el actuar estatal por exigir la mediación de actos del legislador. Por su parte, la garantía institucional puede ser intervenida de una forma más fácil y directa siempre que se garantice la existencia de su núcleo esencial. Esta diferencia es común, tanto para nuestro derecho como para el español que se está cotejando, tal como lo dice José María Baño León:

"La estructura diferencial de ambas figuras queda aún más perfilada —siempre según la concepción clásica de los derechos fundamentales - con sólo observar que los derechos fundamentales son normas cuyo contenido la Constitución prefigura y reserva (al legislador), de tal forma que las limitaciones son tan sólo admisibles en la medida que otros derechos fundamentales lo demanden, mientras que en las garantías institucionales el legislador tiene una gran libertad en configurar su contenido (pues no existe uno predeterminado), y sólo cuando borre por completo tal institución habrá tras pasado la frontera de la inconstitucionalidad" ${ }^{n}[57]$.

Ahora bien, a pesar de la claridad con la que el Tribunal Constitucional español resolvió la discusión existente $^{[58]}$ es importante señalar que, en gran parte, un elemento que permitió solucionar el asunto con relativa facilidad fue la comprensión de que los conceptos de garantía institucional y derecho fundamental no son incompatibles y excluyentes. Esta misma corporación lo reafirma en el mentado fallo:

“(...) Derecho fundamental y garantía institucional no son categorías jurídicas incompatibles o que necesariamente se excluyan, sino que buena parte de los derechos fundamentales que nuestra Constitución reconoce constituyen también garantías institucionales, aunque, ciertamente, existan garantías institucionales que, como la autonomía local, no están configuradas como derechos fundamentales" $[59]$.

Contrastando todo esto con lo dicho por Corte Constitucional de Colombia, hay una similitud en el basamento que utilizó esta corporación para abordar el debate, toda vez que ambos tribunales acuden a la teoría de la garantía institucional nacida y desarrollada en Alemania durante los años veinte del siglo pasado. Sin embargo, ambas entidades llegan a conclusiones diferentes, hecho que resulta un poco extraño al tratarse finalmente del mismo concepto, más allá de las diferencias culturales, jurídicas y políticas propias de cada país.

En este sentido, la Corte Constitucional ha fijado, sin ambages, una postura que coloca a la AU en el escenario de la garantía institucional, descartando de tajo cualquier posibilidad de que sea entendida como un derecho fundamental ${ }^{[60]}$. Esto resulta loable atendiendo a la función esclarecedora que juega muchas veces esta corporación, pero que, al mismo tiempo, se considera que las implicaciones prácticas que tiene esta determinación exigían un pronunciamiento menos radical en su sentido y un poco más matizado, para 
evitar llevar la discusión a términos antagónicos y excluyentes entre la garantía institucional y los derechos fundamentales, tal como en su momento lo hizo en la sentencia T-310 de 1999. En esta se señala que la AU, dependiendo las condiciones, puede tener cualquiera de las dos naturalezas, sin que sea necesario alinderarla en uno u otro extremo de forma pétrea.

\section{Conclusiones}

Terminada la exposición de los puntos anteriores, se pueden obtener varias conclusiones sobre lo estudiado, que pueden concretarse de la siguiente manera:

Primero: Resulta evidente la evolución que ha tenido el concepto de AU dentro de los distintos pronunciamientos judiciales de la Corte Constitucional. La AU es inicialmente interpretada por la Corte Constitucional como un derecho de rango constitucional cuyo titular son las entidades de educación superior. Esto le otorga un rango de acción más o menos amplio, que permite el desarrollo pleno del quehacer académico, y encuentra sus límites en la Constitución, la ley y los derechos de sus estudiantes. Sin embargo, esta concepción fue mutando con el tiempo a la de garantía institucional, lo que implica un cambio sustancial en la naturaleza de la figura y, en la práctica, supone una clara diferencia en las formas en que el Estado puede intervenir cada una de estas figuras.

Segundo: La discusión teórica que hacía a la AU fluctuar entre garantía institucional y derecho fundamental se presentó en otros países, entre ellos España, latitud en la cual su Tribunal Constitucional declaró a la $\mathrm{AU}$ como derecho fundamental, pero señalando que esta noción no rivaliza con la de garantía institucional, pues no son conceptos excluyentes ni antagónicos.

Tercero: La Corte Constitucional Colombiana, en el proceso de evolución que le dio al concepto de AU, adoptó finalmente una postura que se considera radical, al descartar la posibilidad de que la AU sea entendida como un derecho fundamental subjetivo en cabeza de las universidades del país, y al declarar como su única naturaleza la de garantía institucional, lo que supone en la práctica una menor resistencia para el actuar estatal, al momento de intervenir o regular esta institución.

Cuarto: A pesar de la claridad con la que la Corte Constitucional declara a la AU como garantía institucional, se encuentra también que esta misma corporación en fallos recientes continúa refiriéndose a la AU como un derecho constitucional, lo que puede ser un foco de confusión ante el esfuerzo conceptual que esta misma corporación ha venido realizando. Resulta necesario aplicar un mayor rigor en las aproximaciones que se hagan desde la Corte sobre la AU, para que de esta forma se concrete de mejor manera la noción y naturaleza de la figura.

Quinto: Por otra parte, del estudio realizado se encuentra que la Corte Constitucional, con alguna frecuencia, pareciera confundir los alcances de la AU frente a su relación con otras garantías o derechos, tal como ocurre con el derecho a la educación o la libertad de cátedra, instituciones con las que la AU tiene una estrecha relación, pero de las que tiene total independencia en cuanto a sus alcances, fines y titularidad. Debido a ello, resultaría de gran valor para el estado del arte que la Corte sentara posturas más claras y uniformes sobre la relación de la $\mathrm{AU}$ frente otras instituciones con las que constantemente interactúa.

Sexto: La AU no es solo predicable a lo académico, sino que incluye una integralidad universitaria que asegure la posibilidad a las universidades de que puedan cumplir con su función social, enmarcadas en el servicio público de la educación superior.

\section{Referencias}

Alfonso Borrero Cabal, La autonomía universitaria. Breve ensayo histórico y teórico, 5 Uni-pluri/versidad, n. ${ }^{\circ}$ 1, 39-46 (2005). http://aprendeenlinea.udea.edu.co/revistas/index.php/unip/article/view/12201 
Asamblea Nacional Constituyente, 45 Gaceta Constitucional, informe ponencia (13 de abril de 1991).

Asamblea Nacional Constituyente, 5 Gaceta Constitucional, Proyecto de Acto Reformatorio de la Constitución Política de Colombia n. ${ }^{\circ} 2$ (15 de febrero de 1991).

Asamblea Nacional Constituyente, 34 Gaceta Constitucional, Propuestas de Organizaciones No Gubernamentales. Reforma Constitucional n. ${ }^{\circ}$. Asociación Colombiana de Universidades, ASCUN (2 de abril de 1991).

Asamblea Nacional Constituyente, 24 Gaceta Constitucional, Proyecto de Acto Reformatorio de la Constitución Política de Colombia n. ${ }^{\circ} 82$ (20 de marzo de 1991).

Asamblea Nacional Constituyente, 27 Gaceta Constitucional, Proyecto de Acto Reformatorio de la Constitución Política de Colombia n. 113 (26 de marzo de 1991).

Asamblea Nacional Constituyente, 37 Gaceta Constitucional, Proyecto de Acto Reformatorio de la Constitución Política de Colombia n. ${ }^{\circ}$ 126-B (5 de abril de 1991).

Asamblea Nacional Constituyente, 102 Gaceta Constitucional, Comentarios y Propuestas del Articulado sobre la Educación y la Cultura (19 de junio de 1991).

Asamblea Nacional Constituyente, 109 Gaceta Constitucional, Artículos de la Constitución Política de Colombia Aprobados en Primer Debate (27 de junio de 1999).

Asamblea Nacional Constituyente, 114 Gaceta Constitucional, Promulgación de la Constitución Política de la República de Colombia (7 de julio de 1991).

Asamblea Nacional Constituyente, 82 Gaceta Constitucional, Informe-Ponencia: "Carta de derechos, deberes, garantías y libertades" (25 de mayo de 1991).

Corte Constitucional de Colombia. Sala Tercera de Revisión. Sentencia T-492 de 1992 (M. P. José Gregorio Hernández Galindo; 12 de agosto de 1992).

Corte Constitucional de Colombia. Sala de Revisión de Tutelas. Sentencia T-598 de 1992 (M. P. Favio Morón Díaz; 28 de agosto de 1992).

Corte Constitucional de Colombia. Sala Novena de Revisión. Sentencia T-425 de 1993 (M. P. Vladimiro Naranjo Mesa; 26 de septiembre de 1993).

Corte Constitucional de Colombia. Sala de Revisión en asuntos de tutela. Sentencia T-123 de 1993 (M. P. Vladimiro Naranjo Mesa; 16 de marzo de 1993).

Corte Constitucional de Colombia. Sala Tercera de Revisión. Sentencia T-512 de 1995 (M. P. Eduardo Cifuentes Muñoz; 14 de noviembre de 1995).

Corte Constitucional de Colombia. Sala Tercera de Revisión. Sentencia T-180 de 1996 (M. P. Eduardo Cifuentes Muñoz; 30 de abril de 1996).

Corte Constitucional de Colombia. Sala Séptima de Revisión. Sentencia T-515 de 1995 (M. P. Alejandro Martínez Caballero; 15 de noviembre de 1995).

Corte Constitucional de Colombia. Sala Cuarta de Revisión. Sentencia T-02 de 1992 (M.P. Dr. Alejandro Martínez Caballero; 8 de mayo de 1992).

Corte Constitucional de Colombia. Sentencia C-337 de 1996 (M. P. Hernando Herrera Vergara; 1 de agosto de 1996).

Corte Constitucional de Colombia. Sala de Selección Número Tres. Sentencia T-223 de 1996 (M. P. Hernando Herrera Vergara; 16 de mayo de 1996).

Corte Constitucional de Colombia. Sentencia C-220 de 1997. (M. P. Fabio Morón Diaz; 29 de abril de 1997).

Corte Constitucional de Colombia. Sala Primera de Revisión. Sentencia T-513 de 1997 (M. P. Jorge Arango Mejía; 9 de octubre de 1997).

Corte Constitucional de Colombia., Sentencia T-515 de 1996 (M. P. Alejandro Martínez Caballero; 15 de noviembre de 1995).

Corte Constitucional de Colombia. Sala Séptima de la Corte Constitucional. Sentencia T-310 de 1999 (M. P. Alejandro Martínez Caballero; 6 de mayo de 1999). 
Corte Constitucional de Colombia. Sala Quinta de Revisión. Sentencia T-156 de 2005 (M. P. Rodrigo Escobar Gil; 23 de febrero del 2005).

Corte Constitucional de Colombia. Sentencia C-1435 del 2000 (M. P. Cristina Pardo Schlesinger; 25 de octubre de 2000).

Corte Constitucional de Colombia. Sala Quinta de Revisión. Sentencia T-933 de 2005 (M. P. Rodrigo Escobar Gil; 7 de septiembre del 2005).

Corte Constitucional de Colombia. Sala Novena de Revisión. Sentencia T-254 de 2007 (M. P. Clara Inés Vargas Hernández; 12 de abril del 2007).

Corte Constitucional de Colombia. Sala Plena de la Corte Constitucional. Sentencia C-162 de 2008 (M. P. Humberto Antonio Sierra Porto; 21 de febrero del 2008).

Corte Constitucional de Colombia. Sala Tercera de Revisión. Sentencia T-689 de 2009 (M. P. Luis Ernesto Vargas Silva; 1 de octubre del 2009).

Corte Constitucional de Colombia. Sala Cuarta de Revisión. Sentencia T-276 de 2009 (M. P. Gabriel Eduardo Mendoza Martelo; 16 de abril del 2009).

Constitución Española, Art. 27. 27 de diciembre de 1978 (España).

Constitución Política de Colombia [Const]. Art. 41.1 de diciembre de 1885 (Colombia).

Constitución Política de Colombia [Const]. Art. 69.7 de julio de 1991 (Colombia).

Diego Eduardo López Medina, El Derecho de los Jueces, 148 (2a. ed., Legis, 2006).

Gaceta Constitucional de la República de Colombia No. 18 de 8 de marzo de 1991.

Gaceta Constitucional de la República de Colombia No. 25 de 21 de marzo de 1991.

Gaceta Constitucional de la República de Colombia No. 29 de 30 de marzo de 1991.

Gaceta Constitucional de la República de Colombia No. 31 de 1 de abril de 1991.

Gaceta Constitucional de la República de Colombia No. 110 de 28 de junio de 1991.

Gaceta Constitucional de la República de Colombia No. 112 de 3 de julio de 1991.

Gaceta Constitucional de la República de Colombia No. 128 de 15 de octubre de 1991.

Gaceta Constitucional de la República de Colombia No. 129 de 17 de octubre de 1991.

Gaceta Constitucional de la República de Colombia No. 133 de 25 de octubre de 1991.

Ileana P. Beade, Acerca de la relación entre los conceptos de libertad, voluntad y arbitrio en la metafisica de las costumbres, 9 Kant e-Prints, Revista Internacional de Filosofía, n. ${ }^{\circ}$ 2, 58-77 (2014). https://www.cle.unicamp.br/eprints/in dex.php/kant-e-prints/article/view/463/364

Immanuel Kant, La metafísica de las costumbres (A. Cortina Orts y J. Conill Sancho trads., Tecnos, 1994).

Joan Oliver Araujo, Alcance y significado de la "autonomia universitaria" según la doctrina del tribunal constitucional, Revista de Derecho Político, n. ${ }^{\circ} 33,77-98$ (1991). http://e-spacio.uned.es/fez/eserv/bibliuned:Derechopolitic o-1991-33-DEF26126/PDF

José María Baño León, La distinción entre derecho fundamental y garantía institucional en la Constitución española, 8 Revista española de derecho constitucional, n. 24, 155-179 (1988).

Juan José Solozábal Echavarría, Garantía institucional, en Enciclopedia Jurídica Básica (1995).

Ley 30 de 1992. Por la cual se organiza el servicio público de la Educación Superior, Art. 28, 28 de diciembre de 1992. D.O. n. 40700.

Miguel Agudo Zamora, El derecho fundamental a la autonomía universitaria en La legislación española actual, en Derecho Constitucional para el siglo XXI: actas del VIII Congreso Iberoamericano de Derecho Constitucional (Manuel Carrasco Durán, Francisco Javier Pérez Royo, Joaquín Urías Martínez y Manuel José Terol Becerra coords., Ed. Thomson Reuters Aranzadi, 2006).

Tribunal Constitucional de España. Sentencia 26/1987, BOE 71 (M. P. Fernando García-Mon y González-Regueral; 24 de marzo de 1987). 


\section{ANEXOS}

Los anexos tienen como objetivo mostrar de forma gráfica la frecuencia de citaciones de las cien sentencias de la Corte Constitucional revisadas para este estudio, lo cual permite identificar con mayor facilidad aquellos fallos a los que la misma Corte recurre de forma reiterada para sustentar sus decisiones.

En esta primera gráfica se muestran aquellas sentencias que tiene una citación igual o superior a diez (10) en otros fallos, mostrandose así la sentencia con mayor reiteración dentro de la jurisprudencia estudiada.

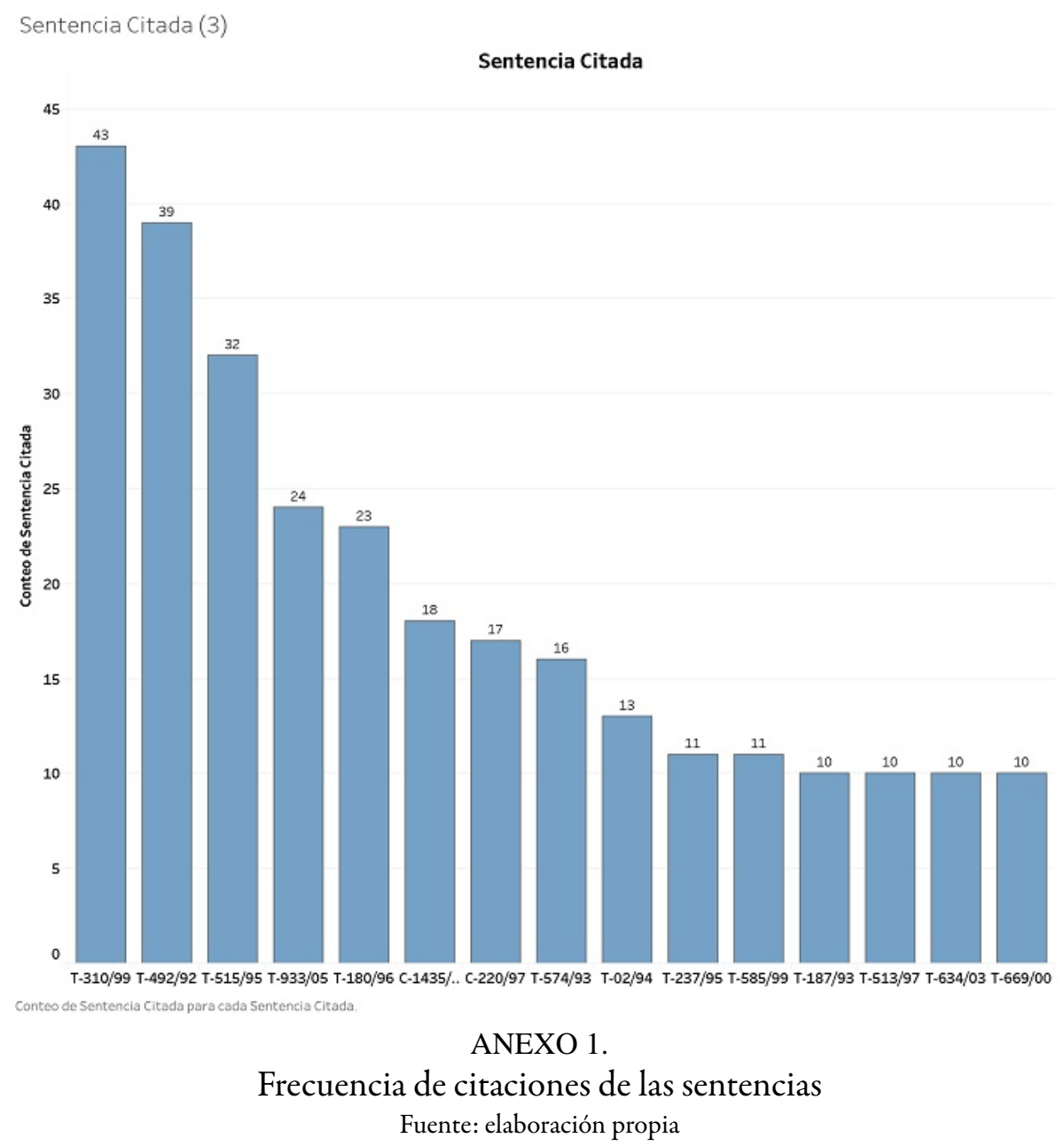

Por su parte, en el anexo 2 se puede identificar con mayor ilustración el volumen de citación de estas sentencias. 


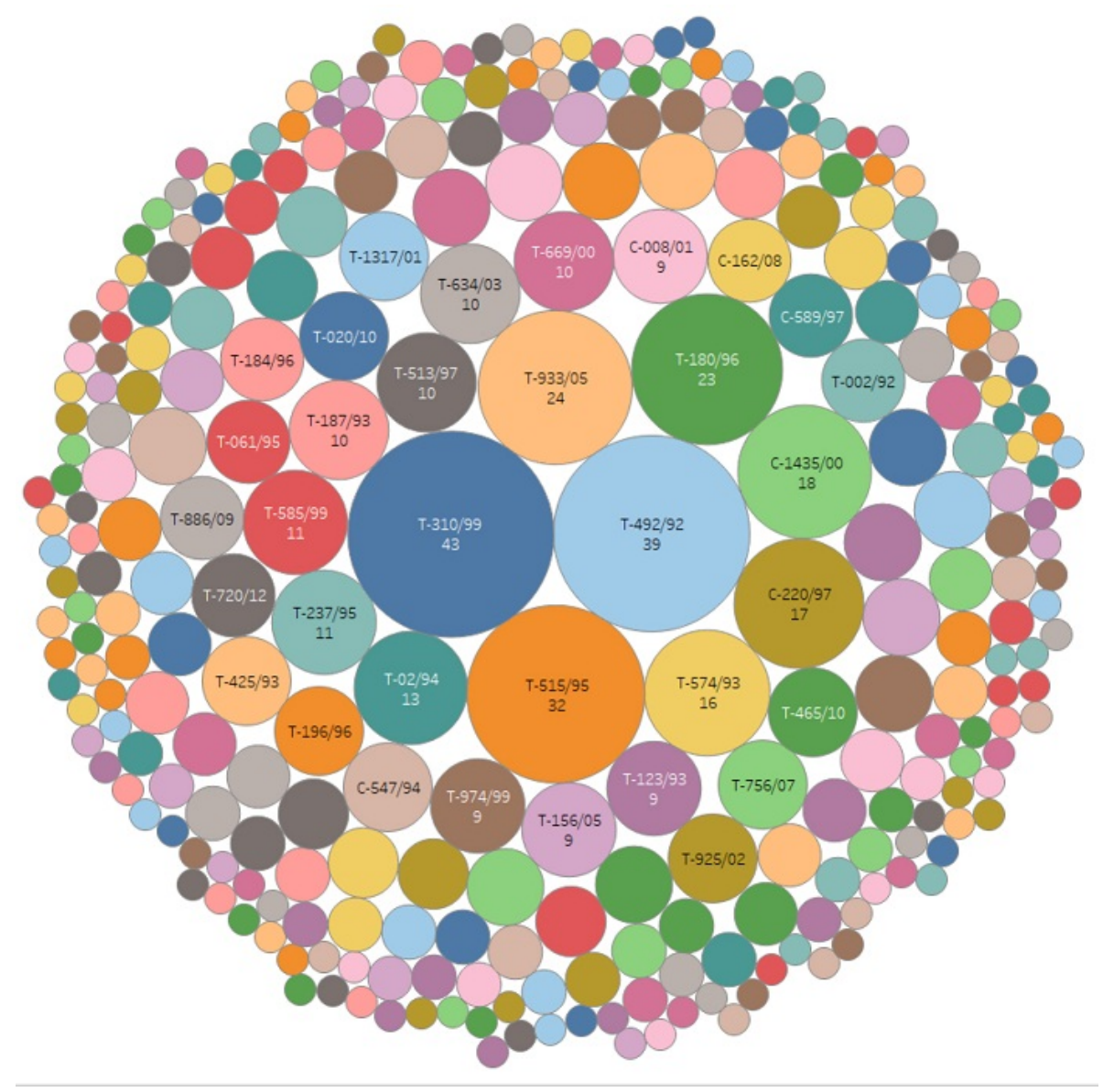

ANEXO 2.

Volumen de citación de las sentencias

Fuente: elaboración propia

Revisados los resultados de estas gráficas, se puede evidenciar que la sentencia T-310 de 1999 es la que tiene mayor reiteración, seguida por las sentencias T-492 de 1992 y T-515 de 1995, que son las que muestran un mayor grado de reiteración. Este hecho no se considera accidental, sobre todo cuando se contrasta con el estudio hecho en este documento, ya que esto guarda total coherencia con los hitos que se han explicado y resaltado.

Por un lado, el fallo T-310 de 1990 que fue ampliamente referido en este escrito, trae un valioso aporte que consiste en un claro resumen de los escenarios constitucionales sobre los cuales la Corte se había pronunciado previamente, estableciendo las reglas o ratio con las que la corporación resolvió las distintas tensiones que se presentaron, igualmente, como se indicó antes, este fallo presenta una mirada dual de la AU como derecho y como garantía, dependiendo los aspectos facticos en que se ejerza.

Por otro lado, la sentencia T-492 de 1992, al ser el fallo fundacional de esta jurisprudencia sobre AU, resulta ser la piedra angular sobre la que se fundamentan muchos pronunciamientos de la Corte, además, porque como se advirtió en su momento este documento, esta decisión hace una clara aproximación a la decisión y alcance de la AU.

Y, por último, la sentencia T-515 de 1995 señala el núcleo esencial de la AU, lo cual resulta de gran valor, más aún cuando se habla de la noción de garantía institucional, porque bajo esta premisa es entonces ese núcleo el que resulta inmodificable para el Estado, razón por la cual es fácil advertir por qué la misma Corte acude con tanta frecuencia a esta decisión. 


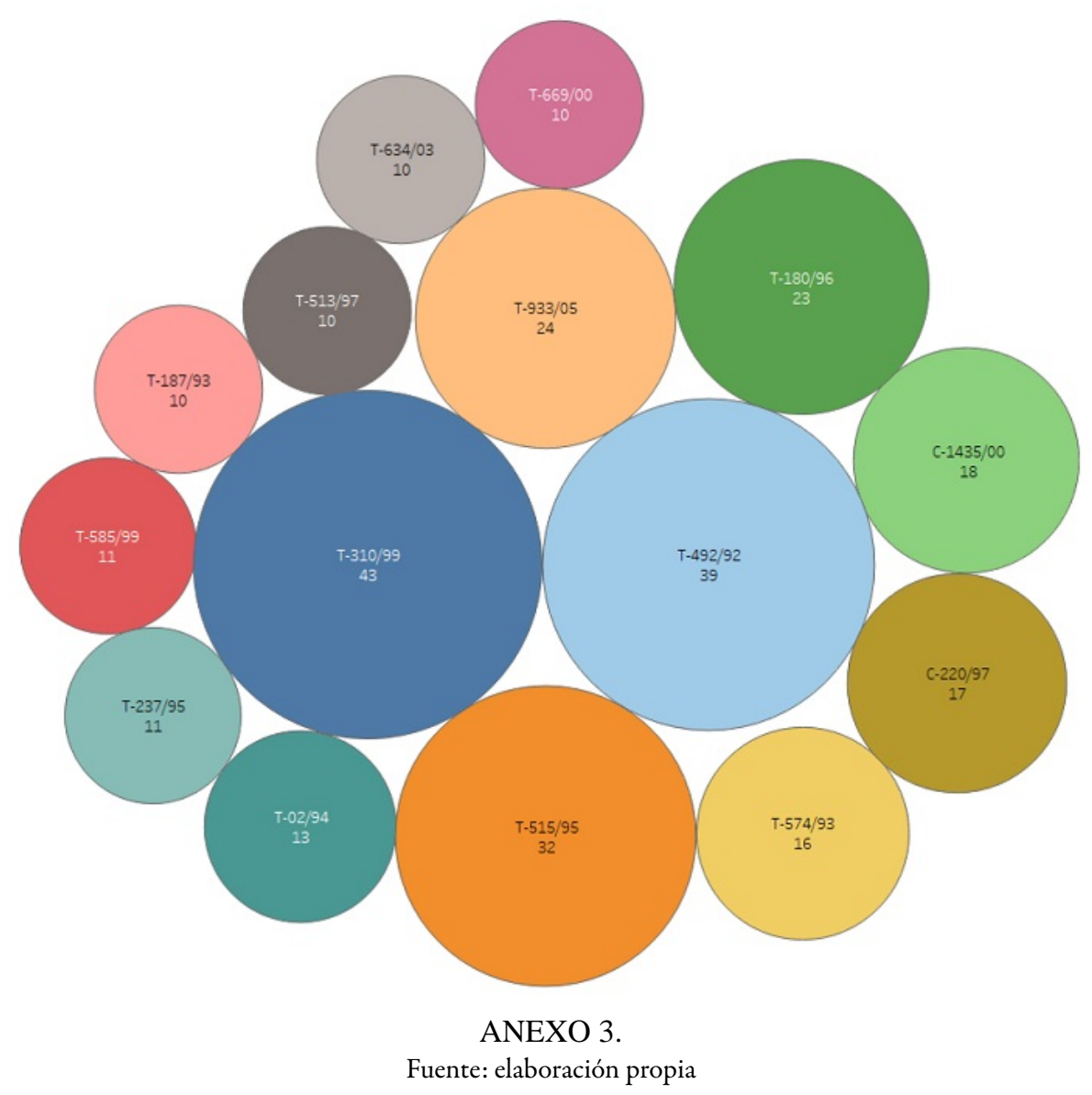

\section{Notas}

* Artículo de reflexión.

[1] En adelante en el presente texto se referirá a la Autonomía universitaria simplemente como AU.

[2] Un "escenario constitucional" es el patrón fáctico típico (con su correspondiente campo de intereses contrapuestos) en el que la corte ha especificado, mediante subreglas, el significado concreto de un principio constitucional abstracto. Véase: Diego Eduardo López Medina, El Derecho de los Jueces, 148 (2a. ed., Legis, 2006).

[3] Se revisaron cien sentencias T, C y SU que la Corte Constitucional ha dictado desde el año 1992 al 2018, las cuales fueron descargadas directamente desde la relatoría del sitio web de la Corte Constitucional de Colombia, y que fueron buscadas con el descriptor "Autonomía Universitaria". https://www.corteconstitucional.gov.co/relatoria/

[4] Constitución Política de Colombia [Const]. Art. 69.7 de julio de 1991 (Colombia).

[5] Se considera que la redacción de este artículo da una clara indicación de la noción que el constituyente tenía de la AU, pues al comparar este texto con el de constituciones como la española, se encuentra esta redacción del artículo 27 numeral 10: "se reconoce la autonomía de las universidades, en los términos que la ley establezca”. (Véase: Constitución Española, Art. 27.27 de diciembre de 1978 (España).A pesar de que a simple vista estas dos redacciones no suponen mayor diferencia, se considera que sí entrañan una importante distinción, ya que la consagración española al usar el verbo reconocer está dejando implícito que la AU es un elemento inherente de la universidad, lo cual se da por derecho propio y no como una dádiva constitucional o legislativa, carácter que Alfonso Borrero S. J. ya había resaltado anteriormente:"De donde parece innecesario consagrar la autonomía en la Carta constitucional, porque el Estado no crea la autonomía del saber universitario. A lo más, por sana lógica, los Estados, como corresponsables de la educación de sus ciudadanos y de los destinos políticos de la ciencia, consagran en sus Constituciones el respetuoso reconocimiento de la autonomía del saber y de la universidad, en previsión de posibles atropellos del Estado mismo y de los gobiernos que ignaros de estos principios, impiden la actividad autónoma universitaria mediante leyes o decretos intervencionistas". Alfonso Borrero Cabal, 
La autonomía universitaria. Breve ensayo histórico y teórico, 5 Uni-pluri/versidad, n. ${ }^{\circ}$ 1, 7 (2005).Ante esto, se acoge la noción de connaturalidad de la AU al afirmar que este es un elemento esencial de toda universidad, cuya existencia no está supeditada a la consagración normativa. Por lo cual se considera que la redacción que hace la Constitución española es más precisa al hacer un reconocimiento de este hecho, que no es de menor calado, pues marca un indicio de la naturaleza jurídica y teórica de la figura.

[6] Vale la pena anotar que la Constitución Política de 1886, antecedente inmediato de la de 1991, solo consagraba un artículo referido a la educación, que señalaba: Art. 41. La educación pública será organizada y dirigida en concordancia con la Religión Católica. La instrucción primaria costeada con fondos públicos, será gratuita y no obligatoria. Constitución Política de Colombia [Const]. Art. 41.1 de diciembre de 1885 (Colombia).

[7] Gacetas Constitucionales de la República de Colombia n. 5, 34, 45, 18, 24, 25, 27, 29, 31, 37, 82, 102, 109, 110, 112, 114, 128,129 y 133.

[8] Asamblea Nacional Constituyente, 5 Gaceta Constitucional, Proyecto de Acto Reformatorio de la Constitución Política de Colombia n. 2 (15 de febrero de 1991).

[9] Gaceta Constitucional de la República de Colombia, n. 5, p. 4, Art. 28, Núm. 7.

[10] Asamblea Nacional Constituyente, 34 Gaceta Constitucional, Propuestas de Organizaciones No Gubernamentales. Reforma Constitucional n. ${ }^{\circ}$, p. 24, Literal A. Asociación Colombiana de Universidades, ASCUN (2 de abril de 1991).

[11] Asamblea Nacional Constituyente, 24 Gaceta Constitucional, Proyecto de Acto Reformatorio de la Constitución Política de Colombia n. ${ }^{\circ} 82$ (20 de marzo de 1991).

[12] Asamblea Nacional Constituyente, 27 Gaceta Constitucional, Proyecto de Acto Reformatorio de la Constitución Política de Colombia n. 113 (26 de marzo de 1991).

[13] Asamblea Nacional Constituyente, 37 Gaceta Constitucional, Proyecto de Acto Reformatorio de la Constitución Política de Colombia n. ${ }^{\circ}$ 126-B ( 5 de abril de 1991).

[14] Asamblea Nacional Constituyente, 102 Gaceta Constitucional, comentarios y propuestas del articulado sobre la educación y la cultura (19 de junio de 1991).

[15] Íd.

[16] Asamblea Nacional Constituyente, 109 Gaceta Constitucional, Artículos de la Constitución Política de Colombia aprobados en primer debate (27 de junio de 1999).

[17] Asamblea Nacional Constituyente, 114 Gaceta Constitucional, Promulgación de la Constitución Política de la República de Colombia (7 de julio de 1991).

[18] Ley 30 de 1992. Por la cual se organiza el servicio público de la Educación Superior, Art. 28, 28 de diciembre de 1992. D.O. n. ${ }^{\circ} 40700$.

[19] La Sentencia T-492 de 1992 surge a partir de la acción de tutela instaurada por Harold Humberto Sarmiento Ramírez contra la Universidad Externado de Colombia para solicitar que se le ordenara a la universidad conferirle el título de Comunicador Social, ya que había sido suspendido definitivamente del centro educativo, luego de adelantarse en su contra un proceso disciplinario en el cual, según el accionante, se violaron sus derechos fundamentales a la defensa y al debido proceso. Corte Constitucional de Colombia. Sala Tercera de Revisión. Sentencia T-492 de 1992 (M. P. José Gregorio Hernández Galindo; 12 de agosto de 1992), p. 11.

[20] Sobre el particular, la Corte Constitucional de Colombia pareciera confundir Autonomía con Libertad, términos que son diferentes, toda vez que al estudiar el concepto de autonomía resulta necesario citar a Immanuel Kant en La metafísica de las costumbres (A. Cortina Orts y J. Conill Sancho trads., Tecnos, 1994), quien hace un estudio detallado de los conceptos de libertad, autonomía, voluntad y arbitrio. Por su parte, Ileana P. Beade, Acerca de la relación entre los conceptos de libertad, voluntad $y$ arbitrio en la metafísica de las costumbres, 9 Kant e-Prints, Revista Internacional de Filosofía, n. ${ }^{\circ}$ 2, 58-77 (2014), afirma que Kant define a la voluntad como "la capacidad de establecer fines, siempre que tales fines sean representados como fundamentos para la determinación de la facultad volitiva" (pág. 61), mientras que el arbitrio responde a la "capacidad de escoger máximas determinantes de la acción y la consiguiente capacidad de actuar según la máxima escogida” (pág. 62). Así mismo, en la concepción anotada, es "posible adscribir a la libertad - como autonomía - a la voluntad, mientras que la libertad como independencia o espontaneidad debe ser referida, en cambio, al arbitrio" (pág. 58). Por tanto, "la independencia del arbitrio, en tanto capacidad 
de determinarse a actuar según una máxima espontáneamente adoptada, es lo que se denomina libertad en sentido negativo, mientras que la capacidad de la voluntad de darse a sí misma una ley es lo que se denomina libertad en sentido positivo" (pág. 64). De manera que se hace evidente, además, que la relación entre los conceptos de libertad y autonomía es una relación de género a especie, respectivamente, reiterando que es la autonomía de la voluntad la manifestación de la libertad en sentido positivo. (negritas y cursivas propias).

[21] Sobre la Sentencia T-598 de 1992, el señor Guillermo Salazar Sea, Personero Municipal de Palmira (Valle), presentó acción de tutela en representación de los estudiantes de la Universidad Nacional de Colombia, Facultad de Ciencias Agropecuarias Seccional Palmira, "por la violación del derecho fundamental a la educación, ya que las directivas de este centro educativo estaba en trámite de efectuar el cierre definitivo de la cafetería y residencias, que funcionan en este centro, lesionando con ello, estudiantes (sic) provenientes de otros departamentos y municipios del Valle del Cauca". Corte Constitucional de Colombia. Sala de Revisión de Tutelas. Sentencia T-598 de 1992 (M. P. Favio Morón Díaz; 28 de agosto de 1992), p. 7.

[22] Sobre la Sentencia T-425 de 1993, el ciudadano Antonio Carlos Pimienta Padilla interpuso ante el Juez Tercero Civil del Circuito de Montería una acción de tutela contra la Corporación Universitaria del Sinú, a fin de que se le amparara su derecho a la educación, y solicita al actor que le permita presentar sus exámenes finales "desprendiéndose de la noción de que se coacciona en lo académico para lograr el resultado económico de la Institución". Corte Constitucional de Colombia. Sala Novena de Revisión. Sentencia T-425 de 1993 (M. P. Vladimiro Naranjo Mesa; 26 de septiembre de 1993), p. 9.

[23] Sobre la sentencia T-123 de 1993, Álvaro Guzmán Orjuela presentó ante el Juzgado Segundo Civil del Circuito de Girardot una acción de tutela contra el Acuerdo 00031992 proferido por el Consejo Académico del Instituto Universitario de Cundinamarca, ITUC, donde el Consejo Superior se comprometió a hacerle llegar algunas observaciones y sugerencias al Consejo Académico para que reconsiderara las medidas adoptadas en el acuerdo 0002 del 27 de noviembre de 1992. Corte Constitucional de Colombia. Sala de Revisión en asuntos de tutela. Sentencia T-123 de 1993 (M. P. Vladimiro Naranjo Mesa; 16 de marzo de 1993).

[24] Sobre la sentencia C-299 de 1994, el ciudadano Carlos Alberto Ballesteros Barón, acude ante esta Corporación con el fin de solicitar la inexequibilidad del párrafo final del artículo 25 del decreto-ley 1210 del 28 de junio de 1993, "por el cual se reestructura el Régimen Orgánico Especial de la Universidad Nacional de Colombia". Corte Constitucional de Colombia. Sala de Sala Plena. Sentencia C-299 de 1994 (M. P. Hernando Herrera Vergara y Vladimiro Naranjo Mesa; 30 de junio de 1994) P. 26.

[25] Sobre la Sentencia T-512 de 1995, Piedad Barona Villafañe presentó una acción de tutela contra la Corporación Universitaria Autónoma de Occidente, debido a que cuando la alumna se disponía a cumplir con los últimos requisitos necesarios para optar al título de ingeniera industrial, la Universidad le informó que debía volver a cursar las asignaturas de Estadística I y Administración I que aparecían como reprobadas en el respectivo expediente académico. Corte Constitucional de Colombia. Sala Tercera de Revisión. Sentencia T-512 de 1995 (M. P. Eduardo Cifuentes Muñoz; 14 de noviembre de 1995), pp. 10-11.

[26] Sobre la Sentencia T-180 de 1996, Nubia Nelly Plazas Olaya presentó una acción de tutela contra la Universidad Libre por considerar que el centro docente vulneró sus derechos fundamentales a la igualdad y a la educación, cuando le negó la posibilidad de presentar en forma extemporánea los exámenes finales que había omitido por razón de su avanzado estado de embarazo. Corte Constitucional de Colombia. Sala Tercera de Revisión. Sentencia T-180 de 1996 (M. P. Eduardo Cifuentes Muñoz; 30 de abril de 1996).

[27] Es interesante señalar que el magistrado ponente de las sentencias T-512 de 1995 y la T-180 de 1996 fue el Dr. Eduardo Cifuentes Muñoz, quien en ambos pronunciamientos claramente esboza a la AU como un derecho inherente a las universidades y cuya finalidad atiende exclusivamente al adecuado quehacer académico de estos entes, no reconociéndose otros objetivos como los que se señalan en la T-425 de 1993.

[28] En este caso la Corte Constitucional decidió acumular el expediente T-76161 al expediente T-68776, los cuales versan sobre dos acciones de tutelas presentadas por dos ciudadanos contra la Pontificia Universidad Javeriana, quienes consideran que la entidad de educación superior vulneró sus derechos al haberlos excluido por bajo rendimiento académico. Corte Constitucional de Colombia. Sala Séptima de Revisión. Sentencia T-515 de 1995 (M. P. Alejandro Martínez Caballero; 15 de noviembre de 1995).

[29] Sentencia T-02 de 1992, donde se cita a Peter Häberle en su artículo: El Contenido Esencial de los Derechos Fundamentales. Corte Constitucional, Sentencia T-02 de 1992 (M.P. Dr. Alejandro Martínez Caballero; 8 de mayo de 1992).

[30] Corte Constitucional de Colombia., Sentencia T-515 de 1996 (M. P. Alejandro Martínez Caballero; 15 de noviembre de 1995), p. 13. 
[31] Sobre la Sentencia C-337 de 1996, el ciudadano Álvaro Sanjuan Sanclemente promovió una demanda en ejercicio de la acción pública de constitucionalidad ante la Corte Constitucional, a fin de que en esta declaren inexequibles los apartes acusados de los artículos 28 y 29 de la Ley 30 de 1992. Corte Constitucional de Colombia. Sentencia C-337 de 1996 (M. P. Hernando Herrera Vergara; 1 de agosto de 1996), p. 8.

[32] Sobre la Sentencia T-223 de 1996, el ciudadano José Domingo Gélvez Arias promovió una acción de tutela contra la Universidad Nacional de Colombia, a fin de solicitar la protección de sus derechos fundamentales a la igualdad, al libre desarrollo de la personalidad, a la educación, al trabajo y a escoger profesión u oficio, solicita que se reintegre en calidad de estudiante de Contaduría Pública y que en consecuencia se ordene la recepción de su matrícula para cursar las asignaturas de Matemáticas III y Econometría, en el primer semestre de 1996. Corte Constitucional de Colombia. Sala de Selección Número Tres. Sentencia T-223 de 1996 (M. P. Hernando Herrera Vergara; 16 de mayo de 1996), p. 9.

[33] El concepto de "libertad jurídica" es definido por Kant como el poder de autolegislarse colectivamente, haciendo coincidir el concepto de libertad con el concepto de autonomía. Immanuel Kant, supra nota 17. La autonomía se entendería como la capacidad de autodeterminación de un colectivo que coincide en el ejercicio de un quehacer fundamental para el Estado sin perder por ello su identidad y consecuente diversidad. Corte Constitucional de Colombia. Sentencia C-220 de 1997. (M. P. Fabio Morón Diaz; 29 de abril de 1997).

[34] Sobre la Sentencia C-220 de 1997, el ciudadano Augusto Hernández Becerra solicitó a la Corte la declaratoria de inexequibilidad del artículo 4 del Decreto 111 de 1996, "Por el cual se compilan la ley 38 de 1989, la ley 179 de 1994 y la ley 225 de 1995 que conforman el Estatuto Orgánico del Presupuesto”. Corte Constitucional de Colombia. Sentencia C-220 de 1997. (M. P. Fabio Morón Diaz; 29 de abril de 1997), p. 16.

[35] Cursiva fuera de texto.

[36] Sobre la Sentencia T-513 de 1997, Carlos Roberto Castro Buenaventura presentó acción de tutela contra la Universidad del Tolima para que se le protegiera el derecho a la educación consagrado en el artículo 67 de la Constitución, pues considera que este fue vulnerado por la entidad acusada, al abstenerse de tramitar su matrícula académica, por no haber anexado el recibo de pago de los textos necesarios para cursar el semestre, requisito establecido en el artículo primero del acuerdo 036 de 1988. Corte Constitucional de Colombia. Sala Primera de Revisión. Sentencia T-513 de 1997 (M. P. Jorge Arango Mejía; 9 de octubre de 1997), p. 5.

[37] Sobre la sentencia T-310 de 1999, varios estudiantes de Derecho instauraron una acción de tutela en contra de la Universidad Libre, ya que estiman violados sus derechos constitucionales a la igualdad, educación y libre desarrollo de la personalidad, solicitan que se ordene a la Universidad que compulse la orden de pago de matrícula para cursar el año lectivo correspondiente. Igualmente, ordene la inclusión de los nombres de los accionantes en el registro académico, listas oficiales y que las notas obtenidas en el transcurso del tiempo cursado sean tenidas en cuenta por la universidad. Corte Constitucional de Colombia. Sala Séptima de la Corte Constitucional. Sentencia T-310 de 1999 (M. P. Alejandro Martínez Caballero; 6 de mayo de 1999), p. 8.

[38] Al respecto pueden consultarse las sentencias T-574 de 1993 M.P. Eduardo Cifuentes Muñoz, T-237 y T-515 de 1995 M.P. Alejandro Martínez Caballero, entre otras. Cursivas fuera del texto.

[39] Corte Constitucional de Colombia., Sala Séptima de la Corte Constitucional. Sentencia T-310 de 1999 (M. P. Alejandro Martínez Caballero; 6 de mayo de 1999), p. 14, 15, 16.

[40] Mediante oficio del 28 de septiembre de 2000, recibido en la Secretaría General el día 2 de octubre del mismo año, el presidente del Senado de la República remitió a la Corte Constitucional el proyecto de ley 119/99 Cámara - 236/00 senado, "POR LA CUAL SE MODIFICA EL INCISO TERCERO DEL ARTÍCULO 57 DE LA LEY 30 DE 1992", con el fin de que este organismo de control resuelva sobre las objeciones de inconstitucionalidad que el presidente de la República le formuló al referido proyecto, las cuales fueron declaradas infundadas por las plenarias de Senado y Cámara.

[41] Sobre el Fallo T-156 de 2005, Juan Sebastián Hernández González, interpuso acción de tutela contra la Universidad de Antioquia - Seccional Urabá, por considerar que se le ha vulnerado su derecho fundamental a la educación, al haberle impedido matricularse en la carrera de Tecnología en Saneamiento Ambiental que se encontraba cursando, aduciendo para ello el bajo rendimiento académico por haber perdido por segunda vez una asignatura. Corte Constitucional de Colombia. Sala Quinta de Revisión. Sentencia T-156 de 2005 (M. P. Rodrigo Escobar Gil; 23 de febrero del 2005).

[42] Corte Constitucional de Colombia. Sala Quinta de Revisión. Sentencia T-156 de 2005 (M. P. Rodrigo Escobar Gil; 23 de febrero del 2005), p. 10. 
[43] Sobre la Sentencia T-933 de 2005, el ciudadano José Jair Patiño Restrepo presentó acción de tutela contra la Universidad de Manizales, debido a que, a pesar de haber cumplido todos los requisitos académicos para la obtención de título de abogado, la universidad le manifiesta que no le otorgará el título mencionado hasta tanto este no se ponga el día en el pago de obligaciones financieras pendientes, lo cual el accionante considera como un hecho que vulnera sus derechos. Corte Constitucional de Colombia. Sala Quinta de Revisión. Sentencia T-933 de 2005 (M. P. Rodrigo Escobar Gil; 7 de septiembre del 2005 ), pp. 17-18.

[44] Sobre la sentencia T-254 de 2007, Leonardo Andrés De Moya Orozco, a nombre propio, interpuso una acción de tutela contra la Fundación Universidad de América, al estimar que dicho ente de educación superior vulneró sus derechos fundamentales a la educación, al debido proceso, al libre desarrollo de la personalidad y a la dignidad humana, al negarle infundadamente su solicitud de reingreso como estudiante de quinto semestre de Ingeniería de Petróleos y abstenerse de considerar su particular situación, relativa a una calamidad doméstica por la que atravesó junto a su familia y que lo obligó a suspender temporalmente sus estudios. Corte Constitucional de Colombia. Sala Novena de Revisión. Sentencia T-254 de 2007 (M. P. Clara Inés Vargas Hernández; 12 de abril del 2007), pp. 19-20.

[45] Corte Constitucional de Colombia. Sala Quinta de Revisión. Sentencia T-933 de 2005 (M. P. Rodrigo Escobar Gil; 7 de septiembre del 2005), p. 29.

[46] Sobre la sentencia C-162 de 2008, Manuel José Sarmiento Arguello solicitó a la Corte Constitucional que declarara la inconstitucionalidad de enunciados normativos contenidos en los artículos 8 y 9 de la Ley 749 de 2002 por considerar que desconocen los siguientes preceptos constitucionales: el artículo 67 (subordinación de la dirección de la educación a la ley); el artículo 68 (competencia del legislador para establecer las condiciones de creación y gestión de los establecimientos educativos); el artículo 69 (principio de autonomía universitaria); el artículo 113 (separación de poderes); y el artículo 114 (cláusula general de competencia del Legislador). Corte Constitucional de Colombia. Sala Plena de la Corte Constitucional. Sentencia C-162 de 2008 (M. P. Humberto Antonio Sierra Porto; 21 de febrero del 2008).

[47] Véase Juan José Solozábal Echavarría, Garantía institucional, en Enciclopedia Jurídica Básica, 20 (1995).

[48] Sobre la sentencia T-310 de 1999, p. 20, la doctrina señala la evolución entre las relaciones de garantía institucional y derecho fundamental en la teoría constitucional. Un primer momento estaría marcado por una contraposición en las figuras, en el cual se destaca el carácter "pre-estatal” del derecho fundamental, al igual que su titularidad individual y su protección mediante mecanismos constitucionalmente predeterminados, en contraste con la garantía institucional la cual solo se encuentra recogida in nuce en la Constitución, pues su régimen jurídico históricamente ha sido configurado por el legislador, su titularidad corresponde a una institución no a un sujeto y carece de mecanismos específicos de protección jurisdiccional. Un segundo momento está caracterizado por la influencia entre ambas figuras, en el cual la construcción del derecho fundamental se verá influida por la contribución institucional, y sobre todo por la estructura homóloga que les dan a ambas instituciones ciertas constituciones como la Ley Fundamental de Bonn.

[49] Sentencia T-310 de 1999, pp. 22-23

[50] Esta fue la noción que estableció la Corte en el fallo T-310 de 1999.

[51] Véase Corte Constitucional de Colombia. Sala Tercera de Revisión. Sentencia T-689 de 2009 (M. P. Luis Ernesto Vargas Silva; 1 de octubre del 2009).

[52] Sobre la Sentencia T-689 de 2009, Silvia Andrea Arzuaga Berreneche y Germán Felipe Correa Castellanos interpusieron una acción de tutela contra la Universidad Colegio Mayor de Nuestra Señora del Rosario, por considerar que la institución vulneró sus derechos fundamentales a la educación y el debido proceso, ya que a pesar de no haber incurrido en ninguna de las causales de pérdida de cupo y haber cancelado oportunamente el valor del semestre, no se les permitió el acceso al sistema electrónico de registro de asignaturas alegando la aplicación del Decreto Rectoral 869 de $1^{\circ}$ de agosto de 2005, en el cual se estableció que el certificado de suficiencia idiomática, previsto inicialmente como requisito de grado, sería exigido para la inscripción de materias, una vez los estudiantes alcanzaran un número de créditos específicos dentro de su respectivo programa académico.

[53] Sentencias T-492 de 1992, T-598 de 1992, T-425 de 1993, T-123 de 1993, T-512 de 1995, T-180 de 1996, T-515 de 1995, T-02 de 1992, C-337 de 1996, T-223 de 1996, C-220 de 1997, T-513 de 1997, T-310 de 1999, C-1435 del 2000, T-156 de 2005, T-933 de 2005, T-254 de 2007, C-162 de 2008, T-689 de 2009.

[54] Sobre la Sentencia T-276 de 2009, los ciudadanos Kattia Montes Hernández y Mario Alfonso Torres Hernández, en actuaciones independientes, formularon acción de tutela contra la Universidad de Sucre con el fin de obtener el amparo de su derecho fundamental de educación mediante la orden judicial de reintegro al claustro educativo accionado para continuar con sus 
estudios superiores. Corte Constitucional de Colombia. Sala Cuarta de Revisión. Sentencia T-276 de 2009 (M. P. Gabriel Eduardo Mendoza Martelo; 16 de abril del 2009), p. 8.

[55] Entre ellas, las más importantes son: la C-337 de 1996; la T-513 de 1997; la T-310 de 1999; la C-162 de 2008 y la T-689 de 2009.

[56] Véase: Miguel Agudo Zamora, El derecho fundamental a la autonomía universitaria en La legislación española actual, en Derecho Constitucional para el siglo XXI: actas del VIII Congreso Iberoamericano de Derecho Constitucional (Manuel Carrasco Durán, Francisco Javier Pérez Royo, Joaquín Urías Martínez y Manuel José Terol Becerra coords., Ed. Thomson Reuters Aranzadi, 2006), p. 7.

[57] Véase: José María Baño León, La distinción entre derecho fundamental y garantía institucional en la Constitución española, 8 Revista española de derecho constitucional, n. 24,157 (1988).

[58] Es importante señalar que los criterios que tuvo en cuenta el Tribunal Constitucional español para determinar la naturaleza de la AU fueron cuatro, que Joan Oliver Araujo resume de buena manera así: "El Tribunal Constitucional define la autonomía universitaria en nuestro sistema constitucional como un derecho fundamental en base a cuatro argumentos o consideraciones: a) el argumento del locus, ubicación o encuadramiento; b) el argumento gramatical; c) el argumento de la voluntad del constituyente; y d) el argumento teleológico o finalista". Joan Oliver Araujo, Alcance y significado de la "autonomía universitaria" según la doctrina del tribunal constitucional, Revista de Derecho Político, n. ${ }^{\circ} 33,77-98$ (1991).

[59] Véase STC 26/1987, fj 4, apartado a), párrafo primero. Tribunal Constitucional de España. Sentencia 26/1987, BOE 71 (M. P. Fernando García-Mon y González-Regueral; 24 de marzo de 1987).

[60] Ver nota de pie de página No. 35 en este documento, que contiene extracto de la Sentencia T-689 de 2009.

\section{Licencia Creative Commons CC BY 4.0}

Para citar este articulo/To cite this article: Luis Felipe Gómez Restrepo, Enrique Quintana López \& Nicolas Calderón Bolaños, Evolución de la definición y naturaleza de la autonomía universitaria en la jurisprudencia de la Corte Constitucional de Colombia, 68 Vniversitas, n. 139 (2019). https://doi.org/10.11144/Javerian a.vj139.edna 